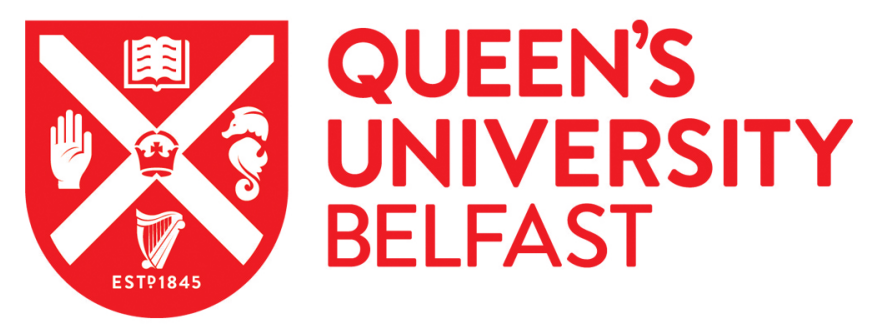

\title{
Clinician-Facilitated Physical Activity Intervention Versus Pulmonary Rehabilitation for Improving Physical Activity in COPD: A Feasibility Study
}

O'Neill, B., O'Shea, O., McDonough, S. M., McGarvey, L., Bradbury, I., Arden , M., Troosters, T., Cosgrove, D., McManus, T., McDonnell, TJ., \& Bradley, J. (2018). Clinician-Facilitated Physical Activity Intervention Versus Pulmonary Rehabilitation for Improving Physical Activity in COPD: A Feasibility Study. COPD: Journal of Chronic Obstructive Pulmonary Disease, 15(3), 254-264. https://doi.org/10.1080/15412555.2018.1486396

Published in:

COPD: Journal of Chronic Obstructive Pulmonary Disease

\section{Document Version:}

Peer reviewed version

Queen's University Belfast - Research Portal:

Link to publication record in Queen's University Belfast Research Portal

\section{Publisher rights}

Copyright 2018 Taylor \& Francis.

This work is made available online in accordance with the publisher's policies. Please refer to any applicable terms of use of the publisher.

\section{General rights}

Copyright for the publications made accessible via the Queen's University Belfast Research Portal is retained by the author(s) and / or other copyright owners and it is a condition of accessing these publications that users recognise and abide by the legal requirements associated with these rights.

Take down policy

The Research Portal is Queen's institutional repository that provides access to Queen's research output. Every effort has been made to ensure that content in the Research Portal does not infringe any person's rights, or applicable UK laws. If you discover content in the

Research Portal that you believe breaches copyright or violates any law, please contact openaccess@qub.ac.uk. 
1 Clinician facilitated physical activity intervention versus pulmonary rehabilitation for improving

2 physical activity in COPD: A feasibility study

3

4 Authors

5 O’Neill B (joint $1^{\text {st }}$ author), O’Shea O (joint $1^{\text {st }}$ author), McDonough S.M,

6 McGarvey L, Bradbury I, Arden M, Troosters T, Cosgrove D, McManus T,

7 McDonnell T.J, Bradley J.M (Senior author)

8

9 Correspondence should be addressed to Dr Brenda O’Neill, Centre for Health and

10 Rehabilitation Technologies (CHaRT), Institute of Nursing and Health Research, School of

11 Health Sciences, Ulster University, Newtownabbey, BT37 0QB, UK. 00442890368812

12 b.oneill@ulster.ac.uk

13

Authors' information:

15

Brenda O'Neill, Centre for Health and Rehabilitation Technologies, Ulster University

United Kingdom, b.oneill@ulster.ac.uk

Orlagh O'Shea, Centre for Health and Rehabilitation Technologies, Ulster University United Kingdom, oshea-o1@email.ulster.ac.uk

Suzanne M McDonough, Centre for Health and Rehabilitation Technologies, Ulster University and UKCRC Centre of Excellence for Public Health (Northern Ireland), United Kingdom, s.mcdonough@ulster.ac.uk

Lorcan McGarvey, Centre for Experimental Medicine, School of Medicine, Dentistry \&

26 Biomedical Sciences, Queens University Belfast United Kingdom, l.mcgarvey@qub.ac.uk 
1 Ian Bradbury, Centre for Health and Rehabilitation Technologies, Ulster University, United

2 Kingdom, ian.bradbury2010@gmail.com

4 Madelynne A, Arden, Department of Psychology, Sociology \& Politics, Sheffield Hallam

5 University, Heart of the Campus, Collegiate Crescent, Sheffield S10 2BQ, United Kingdom

6 m.arden@shu.ac.uk

8 Thierry Troosters, Faculty of Kinesiology and Rehabilitation Sciences, Katholieke

9 Universiteit Leuven, Leuven, Belgium, thierry.troosters@med.kuleuven.be

11 Denise Cosgrove, Northern Ireland Clinical Research Network (Respiratory Health), Belfast

12 Health and Social Care Trust, Belfast, United

13 Kingdom. denise.cosgrove@belfasttrust.hscni.net

Terence McManus, Department of Respiratory Medicine, Western Health and Social Care

16 Trust, Enniskillen.terence.McManus@westerntrust.hscni.net

18 Tim J McDonnell, Department of Respiratory Medicine, St Vincent's University Hospital,

19 Dublin, Ireland, drtimmcdonnell@mac.com

21 Judy M Bradley, Centre for Experimental Medicine, School of Medicine, Dentistry \&

22 Biomedical Sciences, Queens University Belfast, United Kingdom, judy.bradley@qub.ac.uk 
Abstract Pulmonary rehabilitation (PR) may not suit all individuals with COPD and may not result in increased physical activity. Higher levels of physical activity are associated with reduced mortality and morbidity. The aim of this study was to assess the feasibility of conducting a trial to investigate the effectiveness of a clinician facilitated physical activity intervention (PAI) versus PR in improving physical activity in COPD patients referred to PR. In this randomised controlled mixed methods feasibility study all patients referred to PR who were eligible and willing were assessed at baseline and then randomised to the PAI or to PR. Assessments were repeated post intervention and at 3 month follow up. The main outcome was step count measured by Actigraph. Semi structured interviews were conducted post intervention. $\mathrm{N}=50$ patients; mean (SD) age 64.1(8.6)years, 24M were recruited and randomised; $\mathrm{N}=23$ (PAI) and $\mathrm{n}=26$ (PR); one patient was excluded from the analysis as they did not meet the GOLD diagnostic criteria. Key feasibility criteria were met; recruitment was 11\%, dropouts in PAI were 26\% ( $\mathrm{n}=6)$ and 50\% ( $\mathrm{n}=13 / 26)$ PR. Participants in both groups experienced a range of health benefits from their respective programmes. The PAI appears to be effective in increasing step counts in people with COPD: mean change (standard deviation) [confidence interval] for the PAI group was 972.0(3230.3)[-1080.3 to 3024.4], $\mathrm{n}=12$ and 4.3(662.7)[-440.9 to 449.5], $\mathrm{n}=11$ for the PR group. The PAI met all domains of fidelity. This study provides key information to inform a future randomised controlled trial in physical activity. 


\section{Introduction}

3 Globally, pulmonary rehabilitation (PR) is established as a core component in the management of COPD and has been shown to enhance health quality of life, reduce dyspnoea and improve exercise capacity [1]. There is limited evidence to indicate whether the improved exercise capacity following PR translates into improved daily physical activity

7 levels in COPD $[2,3]$. The majority of PR programmes are supervised outpatient-based, and

8 delivered in a group format [4]. Not all patients referred to PR attend for assessment or enroll

9 in the programme after assessment [5], dropouts from and non-adherence rates with PR are

10 high, emphasising that PR may not suit all patients with COPD [5, 6]. Current capacity is

11 unable reach all those with COPD who would potentially benefit from PR [5, 7] and so there

12 is a need to explore alternative platforms for delivering exercise/physical activity

13 interventions traditionally delivered in context of PR .

14

Physical activity is fundamental for the prevention of chronic disease and premature mortality [8]. Walking represents a form of physical activity that has been shown to be effective in increasing physical activity in clinical populations and is necessary for activities of daily living [9]. Although studies in COPD have demonstrated the effectiveness of physical activity interventions [10] particularly individualised walking programmes [11, 12], these alternative programmes do not seem to be offered within current models of healthcare provision for COPD. Interventions have also included different components, for example, use of the internet to record and facilitate the intervention [13], the use of pedometers [14, $15]$, and various behavior change strategies $[16,17]$. However to date a home-based pedometer driven walking intervention in comparison to PR has not yet been explored. A home-based pedometer-driven walking intervention may offer an innovative and alternative 
1 method of delivering physical activity training that could be provided to large numbers of

2 patients with COPD on an individual basis. Walking could provide for flexibility around life

3 commitments and promote a change in activity levels.

4

The importance of conducting a feasibility study prior to a full randomised controlled

6 trial (RCT) has been emphasised by key funders such as the Medical Research Council and

7 the National Institute for Health Research (NIHR), as well as recent publications [18-21].

8 Mixed methods designs can be used in feasibility studies to allow for a greater understanding

9 of patients' perceptions of feasibility, for example barriers to participation [22]. Therefore the

10 aim of this study is to assess the feasibility of conducting a trial to investigate the

11 effectiveness of a clinician facilitated physical activity intervention (PAI) (physical activity

12 consultation and a pedometer-based walking programme) versus PR in improving physical

13 activity in COPD patients referred to PR.

14 Objectives

15 I. To use the NIHR criteria (Table 1) to assess the feasibility of conducting a trial to compare the effectiveness of PAI versus PR in patients with COPD referred to PR

18 II. To explore the views and experience of participants relating to their satisfaction and perceived benefits of a PAI and of PR.

20 III. To assess the feasibility and fidelity of delivering a PAI intervention to patients with COPD

\section{Methods}

24 The reporting of this trial adheres to the Template for Intervention Description and

25 Replication (TIDieR) and the Consolidated Standards of Reporting Trials (CONSORT)

26 statement $2010[23,24]$, online supplement eTable 1. 


\section{Design}

2 The study design was a multicenter mixed methods randomised, parallel-group, feasibility

3 study. The study was registered at https://clinicaltrials.gov/. Ethical approval was obtained

4 from the Northern Ireland Research Ethics Committee 13/NI/0014.

\section{Population}

7 Patients with COPD $(n=50)$ referred for PR to any of the eight sites that provide PR within

8 two Health and Social Care (HSC) Trusts in Northern Ireland were included. All PR sites

9 reported that they were adhering to the BTS guidelines for Pulmonary Rehabilitation prior to

10 the commencement of and midway through the study [4]. Patients with a primary diagnosis

11 of COPD, a good understanding of written English (as reported by the individual patient) and

12 in a stable phase (no change in symptoms or medication in previous 4 weeks) at the time of

13 assessment were included. Spirometry was provided by the PR team and when necessary

14 COPD diagnosis was confirmed with the site PI. Exclusion criteria were inability to safely

15 take part in a walking programme or PR (e.g. unstable angina, neurological, spinal or skeletal dysfunction affecting ability to exercise) as decided by the PR team or inability to comprehend or follow instructions (e.g. dementia).

\section{Recruitment and randomisation}

20 Participants were randomly assigned to two groups using computer-generated block random numbers by a member of team not involved in any other aspect of the study in order to ensure

22 allocation concealment: Group 1-PAI or Group 2- PR. The allocation was retained in sealed envelopes which were opened to reveal group allocation only after consent and after completion of baseline assessment. Patients were stratified according to HSC Trust to help 
1 ensure that equal numbers of patients within each Trust were randomised to each group.

2

As this was a feasibility study, no formal sample size calculation was used. Based on previous publications a sample size of 50 was deemed appropriate to achieve the aims/objectives of this study [25]. This sample size also reflected a realistic target for the intervention period and one which was anticipated would provide sufficient information on the feasibility to inform future studies.

\section{Interventions:}

Participants were randomised to either the PAI or PR.

Physical Acitivity Intervention

The PAI intervention was a 12 week clinician facilitated pedometer driven walking programme. All participants were provided with an unsealed Yamax Digiwalker CW700 so they could record and see their daily step count during the PAI, and as a manual with weekly step diary and action and coping plans. Per protocol participants had weekly contact with the interventionist (specifically trained physiotherapist or nurse (details on the training are available in 2)); weeks 1 to 6 were face to face, weeks 7-11 were conducted by telephone.

Week 12, the final consultation was delivered face to face as planned. Individual face to face consultations were expected to last up to one hour and were conducted in an outpatient hospital department and telephone consultations were expected to last about 15-20 minutes and were iniated by the clinician at an agreed time. Consultations were expected to transition from face to face towards telephone based consultations by about week 6 anticipating that participants would become more familiar and more confident with the intervention, and also to offer flexibility. Regardless, all components of the consultatiions were expected to be delivered. The PAI considered the, 'capability', 'opportunity', 'motivation' and 'behaviour,' 
1 (COM-B) model of behaviour change [26] and included 20 behaviour change strategies [27].

2 Each week participants set a step goal based on their previous weeks step count, as well as

3 the results of a self-efficacy walk (how many steps the participant walked in ten minutes) [9].

4 This step goal was individual to the patient. An example of how the weekly step goal was set

5 is available in the eTable 3. Participants wore pedometers each day during the intervention

6 period for motivation and feedback, and also kept a written step diary which was contained

7 with the intervention manual supplied to them. At each subsequent consultation the

8 clinicians and participants revisited the daily steps of the previous week and reviewed the

9 step goal to assess if it was met/not met or partially met; barriers to physical activity were

10 identified and strategies developed to overcome these; and specific strategies to increase

11 walking were identified. Action and coping plans were made each week led by the participants, and during these consultations clinicians focused on helping participants to build self-efficacy, encouraging social support, providing disease specific education; participants were given the Living Well With COPD for PR booklet [28]. An outcome goal relating to an activity or function was also set at baseline, for example "To be able to walk to the centre of town on my own without fear." This was reviewed during the intervention; at consultation 6 and, if it was already met or participants felt it was too difficult it was revised or amended. The outcome goal was then reviewed at the end to determine whether it was achieved. Pulmonary Rehabilitation

20 PR was delivered by clinicians' as per usual clinical practice. These programmes were 21 delivered in either hospital or health centre outpatient departments. Participants attended a supervised exercise class twice a week for 6 weeks and were also given a booklet with exercises and encouraged to perform these independently on a third occasion. PR also consisted of centre based disease specific education, at which time participants could engage in discussion and ask questions. Participants were also given the Living Well With COPD 
1 for PR booklet [28]. The exercise component usually lasted for one hour and PR sites

2 reported that it generally consisted of cardiovascular exercises and lower and upper body

3 strengthening exercises. A diary was used to record the exercises undertaken and the level of

4 breathlessness measured with on Borg scale. Education sessions (30-60 minutes) were

5 delivered at least once weekly.

\section{Data collection}

7 All screening, recruitment, adherence (number of sessions attended) and drop outs as well as

8 the occurrence of adverse events were recorded, intervention adherence was set at 75\% [29].

9 Demographics (gender, age, height, weight), medical and social details (living arrangements

10 and employment status) and spirometry results were gathered at the baseline assessment.

11 Patients attended four study visits for outcome assessment: baseline assessment was

12 conducted over two appointments 7 days apart (Visit 1 and 2). Participants were assessed

13 again post-intervention (Visit 3) and at 3 months following the end of the intervention (Visit

14 4). All data was collected by a trained independent assessor not involved in the delivery of

15 intervention; a physiotherapist and/or a research assistant.

16

The following outcome measures were collected from all participants: physical

18 activity with the Actigraph ${ }^{\circledR}$ GT3X+ accelerometer [30] and a sealed Yamax Digiwalker

19 CW700 [31] pedometer which were worn around the waist for seven days during all waking

20 hours, as well as the long form of the International Physical Activity Questionnaire (IPAQ)

21 [32]; exercise capacity with the Incremental Shuttle Walk Test (ISWT) [33]; health status

with the COPD Assessment Test (CAT) [34] and EQ5D5L [35]; and a modified Global

23 Rating of Change (GROC) Scale [36]. Participant stage of change [37] was assessed at

24 baseline (Visit 1 and 2). 


\section{$1 \quad$ Patient views}

2 Semi structured interviews were conducted post intervention (visit 3) with all available

3 participants. The semi structured interview script is available in the e-supplement (eTable 4).

\section{Feasibility and fidelity of the PAI}

Participants in the PAI group set a weekly step goal. The step goal and the actual step count achieved by the participant were recorded and analysed to assess whether participants achieved their goal each week, and the degree of change. Additionally, an outcome goal was set at baseline, and at the post intervention assessment (visit 3) participants were asked to report the extent to which they met this goal on a visual analogue scale (0-10) with ten being "fully met". The PAI was considered to be feasible based on whether participants could achieve their weekly step goal, achieve their overall outcome goal, and increase their step count across the intervention.

Fidelity of the PAI was assessed using the checklist published by Borrelli (2011) [38].

This checklist was developed using the treatment fidelity framework provided by the National Institute of Health (NIH) Behavioral Change Consortium (BCC) [39] which includes five domains of treatment fidelity (Study Design, Training of providers, Delivery of treatment, Receipt of treatment, and Enactment of treatment skills). Under each of these domains, there are a number of items with which fidelity is assessed. Further details on the assessment of fidelity are available in the online supplement, eTable 2.

\section{Data analysis}

All participant screening and outcome measure data was entered into Statistical Package for Social Sciences (SPSS) version 22.0 (SPSS Inc., Chicago, IL). Data entry was independently assessed for accuracy and analysed per protocol. All continuous variables were checked for 
1 normal distribution using the Shapiro-Wilk Test, which confirmed that most of the data were

2 normally distributed; BMI, FEV1\% and FVC were not normally distributed. Descriptive

3 statistics were used to summarise the screening, recruitment, adherence and population

4 demographics. Only Actigraph data that contained a minimum of five days of ten hours wear

5 time were used for analysis; and only sealed pedometer data that had a minimum of five days

6 of 100-50,000 steps were used for analysis [40,4]. As this was a feasibility study, we were

7 not focused on statistical significance and therefore mean (standard deviation) (SD)

8 difference, with $95 \%$ confidence interval (CI) was estimated at each follow-up time point for

9 all outcome measures using paired $t$ tests. Data is presented mean ([95\% CI] or (SD)), and

10 nominal data is presented as percentages.

11

Qualitative data was analysed using Kings Template analysis [42]. A template of predefined themes was created using the semi structured interview schedule as guidance. The transcripts were analysed with the predefined themes, and subthemes were added to ensure all relevant text was being captured and coded. All transcripts were checked to ensure all relevant text had been coded according to the final template, and two researchers outside the team reviewed three transcripts each.

All unsealed pedometer data relating to weekly step goals and steps achieved were recorded in Microsoft Excel 2010. Mean weekly step goals and mean weekly steps achieved were calculated and plotted graphically so as to demonstrate how these numbers tracked each other over time during the PAI. The mean difference between participants' first and last recorded mean daily unsealed pedometer step count was also calculated. Finally participants VAS scores for whether they felt they had achieved their outcome goal were also recorded and a mean score calculated. 


\section{$1 \quad$ Results}

\section{Participants}

3 Participant flow through the study is summarised in Figure 1. Six hundred and fifty one

4 patients were screened between $4^{\text {th }}$ April 2014 and $27^{\text {th }}$ July 2015 . Of those eligible $11 \%$

$5(n=50 / 453)$ were recruited over a 16 month period (see eTable 5 in the online supplement for

6 full screening data). $\mathrm{N}=50$ participants with a mean (SD) age of $64.1(8.6), 24 \mathrm{M}$ and $\mathrm{FEV} 1$

$71.4(0.6) \mathrm{L} / \mathrm{min}$ were recruited . Patients were assessed and randomised to the PAI ( $\mathrm{n}=24)$ or

8 PR ( $\mathrm{n}=26)$. One participant who was randomised to the PAI made a mistake and attended PR.

9 Therefore $n=27$ attended PR and $n=23$ attended the PAI. A further $n=1$ participant

10 randomised to PR was exlcuded from the analysis as subsequent information about their

11 diagnosis revealed they did not meet the GOLD criteria for COPD [43]; therfore $n=49$ have

12 been included in the analysis: $n=23$ PAI; $n=26$ PR.

13

\section{Intervention adherence}

20

There were 26\% (n=6/23) drop outs/non-starters in the PAI group. Reasons for not starting and drop outs are detailed in Figure 1. The PAI was adhered to (attended 75\% sessions) by $17 / 17(100 \%)$ of those who did not drop out [29]. The time taken to compete the intervention was 12.4 weeks, ranging from 10.7 to 16.3 weeks and participants on average completed a 
3 starting and drop outs are detailed in Figure 1. PR was adhered to (attended $75 \%$ sessions) by

$4 \quad$ 9/13 (70\%) of those who did not drop out [29]. Participants who adhered to PR attended a

5 mean (SD) of $10.5(1.2)$ of the 12 planned classes.

6

The numbers are too small to fully explore if there were any patterns in the characteristics of dropouts, although in both groups it does appear that those who dropped out were younger than completers: in the PAI dropouts had a mean (SD) age of 58.3 (8.9) years and completers 62.6 (7.6) years and in the PR group dropouts had a mean (SD) age of 65.2 (8.1) years and completers 69.1 (7.3) years.

Figure 1 also details the retention rates for participants providing post intervention (visit 3) and follow up (visit 4) outcome measures: post intervention n=18/23 (78.3\%) (PAI) and $n=19 / 26(73.1 \%)(P R)$ and at follow up $n=15 / 23(65.2 \%)(P A I)$ and $n=18 / 26(69.2 \%)$ (PR). These numbers relate to participants providing at least one outcome measure. Some participants did not adhere to their intervention but returned for outcome measure assessment.

\section{Outcome measures}

A range of outcome measures were included in this study. The mean (SD) time taken in minutes to administer the study outcome measures across all four visits ( 3 time points) was under one hour per visit (59.9 (15.2) minutes). The number of available outcome measures and reasons for missing data at each time point are available in eTable 7 in the online supplement. 
2 Post intervention (visit 3)

3 The mean (SD) daily step count as recorded by the Actigraph for the PAI group at baseline

4 was 3305.6 (1960.2) steps for $\mathrm{n}=17$ participants, and at post intervention was 4768.2 (2992.2)

5 steps for $\mathrm{n}=14$ participants; the mean difference (SD) [CI] was $972.0(3230.3)$ [-1080.3 to

6 3024.4], $n=12$. The mean (SD) daily step count as recorded by the Actigraph for the PR

7 group at baseline was 3834.6 (2245.5) steps for $n=23$ participants and at post intervention

8 was 3476.6 (2307.9) steps for $n=12$ participants; the mean difference (SD) [CI] was 4.3

9 (662.7) [-440.9 to 449.5], $\mathrm{n}=11$. The mean (SD) moderate-vigorous physical activity

10 (MVPA) in minutes as recorded by the Actigraph for the PAI at baseline was 14.3 (15.3) for

$11 \mathrm{n}=17$ participants, and at post intervention was $24.4(26.0)$ for $n=14$ participants; the mean

12 difference (SD) [CI] was 6.6 (26.8) [-10.4 to 23.7] minutes, $\mathrm{n}=12$. The mean (SD) MVPA in

13 minutes as recorded by the Actigraph for the PR group at baseline was 13.9 (15.2) for $\mathrm{n}=23$

14 participants and at post intervention was 12.8 (20.0) for $n=12$ participants; the mean

difference (SD) [CI] was 0.9 (6.0) [-3.2 to 4.9] minutes, $\mathrm{n}=11$.

In relation to exercise capacity and quality of life; participants in the PAI had a mean (SD) distance of $253.0(118.8) \mathrm{m}$ at baseline, $\mathrm{n}=23$ and 288.1 (107.0) $\mathrm{m}$ post intervention for $\mathrm{n}=16$ participants; the mean difference (SD) [CI] was $-11.9(90.4)$ [-60.1 to 36.3] m, n=16.

19 Participants in the PR group had a mean (SD) distance of 259.2 (140.6) $\mathrm{m}$ on the ISWT at 20 baseline, $\mathrm{n}=26$ and 280 (139.7) $\mathrm{m}, \mathrm{n}=17$ post intervention; the mean difference (SD) [CI] was $21-7.6(69.9) \quad$ [-43.6 to 28.3] $\mathrm{m}, \mathrm{n}=16$. For the CAT score participants in the PAI had a mean score of 23.8(6.9) at baseline, $n=23$ and $22.5(7.0)$ at post intervention, $n=17$; the mean difference (SD) [CI] was $0.6(7.7)$ [-3.3 to 4.6], $\mathrm{n}=17$. Participants in the PR group had a

24 CAT score of 18.7 (7.3) at baseline for $\mathrm{n}=26$ and a post intervention CAT score of 16.6 (5.3), $\mathrm{n}=19$; the mean difference (SD) [CI] was $-0.4(6.4)[-3.5$ to 2.7$], \mathrm{n}=19$. The full baseline to 
1 post intervention results for all outcome measures are available in the online supplement,

2 eTable 8.

$5 \quad$ Follow up at 3 months (visit 4)

6 As recorded by the Actigraph there appears to be a general trend towards increasing step

7 counts (mean (SD)) across the three time points in the PAI group: baseline step count 3305.6

8 (1960.20, n17, post intervention step count 4768.2 (2992.1), $\mathrm{n}=18$ and 5332.0 (3070.7) steps

9 at follow up, $n=15$. In the PR group there was a decline in step count (mean (SD)) from

10 baseline to post intervention, and then an increase at follow up: baseline step count 3946.2

11 (2263.1), $\mathrm{n}=24$, post intervention step count $3476.6(2307.9), \mathrm{n}=19$, and a step count of

$124984.6(3598.0)$ at follow up.

\section{Adverse events (AEs)}

14 There were 4 related and unexpected AEs; PAI $(n=3)$ : blister on the right heel and big toe,

15 flare up of a knee swelling, reaction to nickel on pedometer due to a nickel allergy; and, PR

$16(\mathrm{n}=1)$ : dizziness when leaving out patient department after an appointment. These AEs were

17 managed by providing advice to the participant for resolution, and no-one withdrew based in

18 these AEs.

19 Qualitative interviews

$20 \mathrm{~N}=32$ participants were available to complete the semi structured interviews; $n=16 / 23$

21 (69.6\%) PAI; $n=16 / 26(61.5 \%)$ PR. Reasons for not being available for semi structured are

22 detailed in the online supplement, eTable 4. Five core themes were identified: (i) Perceived

23 benefits and impact of the PAI/PR on health, (ii) Views and satisfaction with content of 
1 PAI/PR, (iii) Adherence to the PAI/PR, (iv) Views about the outcome measures and (v)

2 Views about continuing exercise. Participants in both groups enjoyed their respective

3 programmes and experienced a range of benefits across their physical and mental health and

4 also in terms of their social functioning. Participants were generally satisfied with their

5 allocation; participants in the PAI felt the intervention was tailored specifically to them and

6 the pedometer and step diary were well received. Participants in the PAI were generally

7 satisfied with mix of phone and face to face contact. There were mixed views about the

8 duration and frequency of contact; a small number in both the PAI and the PR group felt they

9 could have engaged in the programme for longer, others in the PR group felt that twice

10 weekly was too intense given they had other commitments. Adherence to the programmes

11 were explored; participants in both groups encountered a number of barriers to participation

12 including their health, weather, lack of social support as well as time and other commitments.

13 Participants in PR also reported the group setting and a lack of motivation as barriers.

14 However a number of facilitators were also recorded across the interviews including their

15 own intrinsic motivation, social support and the staff. The pedometer and action and coping

16 plan as well as developing their own strategies to overcome barriers were themed as

17 facilitators for the PAI group. The group setting of PR was a facilitator for some. There were

18 mixed views about the outcome measures; there were some participants who did not mind

19 them, while others found them/parts of them burdensome. The majority of participants

20 planned on continuing to engage in exercise/PA with specific plans including continuing to

21 set goals and use the pedometer or join an exercise class. Participants in both groups were generally quite confident they would continue as the benefits achieved served as motivation.

\section{Feasibility and Fidelity of the PAI}

24 In relation to the achievement of weekly step goal, participants appeared to overachieve their 
1 step goals in the first week of the PAI, but as the intervention progressed the step goal and

2 step count achieved aligned more closely (Figure 2). For those who provided step counts at

3 two time points, most patients $(n=17 / 20)$ demonstrated an increase in their step count

4 following the PAI (Figure 3), n=13/20 met the MCID for step count (600-1100) [44]; step

5 count recorded by the unsealed pedometer improved by a mean (SD) 2,087(2452) steps

6 between week 1 and the last step count recorded. Following the PAI, participants rated

7 whether they had met their outcome goal set out at the start of the intervention using the VAS

8 scale $(0=$ not met at all, $10=$ fully met $)$. VAS scores were available for $n=16 / 18 ; n=1$ was

9 unwell and did not travel for outcome measure collection and $n=1$ could not remember their

10 outcome goal. Overall these participants reported achieving their outcome goal; mean (SD)

$118.8(2.9)$.

Results were obtained from the assessment of fidelity for the five domains of treatment fidelity i.e. (i) Study design: all items under this domain were met except for one

14 (5/6 items were met). (ii) Training of providers: all items under the domain about training of 15 providers were met. (iii) Delivery: a proportion of consultations $n=36 / 221$ (16\%) were 16 assessed and in this sample the majority of the components were delivered as intended 17 ( $n=43 / 50)$. (iv) Receipt and (v) Enactment domains focus on the participants. For receipt most items were fully received with only a few $(n=3 / 18)$ items received on $<100 \%$ of occasions. For enactment a few $(n=2 / 6)$ items were not fully enacted. Further details on the results of fidelity of the PAI are available in the online supplement, eTable 4

\section{Discussion}

This feasibility study demonstrates key considerations for conducting a future trial of a PAI

24 versus PR in COPD. The applicable NIHR criteria for the success of a feasibility trial were met and based on the results of this study, including the qualitative data, a future trial is 
1 feasible. The PAI was effective for increasing step count, feasible to deliver and had good

2 fidelity. However, before proceeding to larger trial strategies for increasing recruitment,

3 reducing dropouts, improving adherence, and for optimising the efficiency of data collection

$4 \quad$ would need to be considered.

5

6 Recruitment to this study was generally feasible; we planned to recruit over a period of 14

7 months and achieved our target number at 16 months. Our recruitment process for this

8 feasibility study was uniquely influenced by opportunities for easy access to programmes

9 within limited study resources; we confined the study to two HSC Trusts and we recruited $11 \%$ of those eligible. Recruitment rates can vary across the COPD literature. For example, recruitment rates of $3.9 \%(103 / 2646)$ in a recent study exploring the feasibility of conventional PR versus a web based PR [45] and 63.3\% 57/90 in a cohort study on PR in COPD [28] have been reported. In research on PAIs in COPD, 18.1\% (140/775) were recruited in a study exploring the effects of a short-term (3 months) and a long-term (18 months) exercise program on self-reported disability and physical function in COPD [46] and $89.8 \%(71 / 79)$ in a study exploring the effects of supervised high intensity continuous or interval training with unsupervised self-paced training [47]. A large number of patients referred to the PR clinics proved not to be suitable for this study due to e.g. musculoskeletal problems, vascular problems, cardiac issues $(198 / 601,33 \%)$; our criteria helped us to identify these patients and triage their care to an appropriate service, test or procedure prior to further assessment for PR. Not all patients referred for PR were interested in taking part ( $n=131 / 601$, $22 \%)$, and a small number $(44 / 601,7 \%)$ had COPD but this was not the primary diagnosis and were therefore excluded. This study provides data to estimate the number of sites that would be needed for a larger trial; the estimated sample size for full scale trial is 150 (75 per group) to allow us to detect a 1500 steps between group difference with $80 \%$ power, taking 
1 into account the current minimally clinical important difference for this population [44].

2 Alternative trial designs could also be considered, for example a non-inferiority trial design

3 or a preference randomised controlled trial [48, 49]. Broader inclusion criteria, as well as

4 more PR sites, could improve the recruitment rates. To achieve recruitment targets for a

$5 \quad$ larger trial we would need to explore the capacity for recruitment at each PR site.

6

The dropout for the PAI (26\%) was lower than the dropout in PR (50\%). Although

8 patients who dropped out were younger than completers this pattern and other differences in

9 important characteristics between dropouts and completers would need to be explored in a

10 larger data set. A number of participants in the current study also dropped out of PR for

11 health reasons, patients with COPD can experience frequent exacerbations and often present

12 with a number of comorbidities [5]. There were other patient reported barriers to participation

13 in the PR group that had the potential to be overcome in the PAI; the individualised and

14 flexible nature of the PAI as well the opportunity for phone contact could have facilitated

15 participation for participants who did not enjoy the PR group setting, had transport

16 difficulties or were restricted due to other commitments. The qualitative component further

17 explored barriers to adherence; the results indicate a need for a more personalised approach

18 and stronger emphasis on identifying each individual's facilitators to help promote adherence.

19 Furthermore the dropout rate for PR (50\%) was higher than that reported (29\%) in a recent

20 PR audit conducted in England and Wales [5]. Reasons for this higher rate of dropout are

21 unclear, and previous studies in PR in the Northern Ireland COPD population have reported

22 dropout rates which are more consistent with the rest of the UK (between about 10\%- 28\%)

$23[28,50]$; therefore, dropout rates from PR could possibly be reduced through the

24 implementation of quality assurance measures prior to a future study. 
A high number of participants did not meet the wear time criteria for the Actigraph

2 [40]. A future trial could consider less stringent wear time rules to optimise data or consider a

3 utilising a different monitor. The qualitative research findings indicated that a small number

4 of people found the belt uncomfortable and at times cumbersome. Even though this was a

5 small number of people, in a study with such a small sample size any loss of data will affect

6 the overall outcome. Although the Actigraph GT3X is considered one of the most valid

7 activity monitors for measuring physical activity in people with COPD [51], a future trial

8 should explore with patients where they are most likely to wear an activity monitor e.g. wrist,

9 thigh, ankle, or waist. Popular activity monitors such as the Fitbit have been validated in

10 people with COPD and could be considered in a future trial to maximise physical activity

11 data [52]. Finally step count was also assessed with a pedometer which was sealed (to hide the step count data) at baseline and again post intervention. There were discrepancies between the Actigraph step count data and pedometer data. Current evidence indicates that these two devices are not interchangeable $[53,54,55]$. The Actigraph is a more precise measure of physical activity and so it may be more suitable for data collection as an outcome measure for research [53]. The pedometer (unsealed) however did appear to be a feasible tool for setting and monitoring step counts during the PAI and it provided good motivation to participants.

The PAI appears to be safe to deliver; with few and minor adverse events. Recording

21 of achievement of weekly step goals as an indication of feasibility has been reported in other studies [56]. Throughout the intervention the step goals and actual steps achieved were

23 closely matched with most participants achieving their goal each week similar to other studies in clinical populations [9]. The greatest improvement was observed in the first week with smaller, more gradual improvements over time; perhaps just wearing the monitor in the 
1 first week provided an initial motivation. The pedometer data obtained from participants

2 during the PAI demonstrated (for those who recorded step counts at two time points) a mean

3 increase $(2,087)$ almost double that of the upper end of the minimally clinically important

4 difference (MCID) for step count in the COPD population (600-1100) [44]. Furthermore,

5 based on the Actigraph data the MVPA also increased, albeit there is not MCID available for

6 MVPA in COPD. Thereby indicating the potential efficacy of this intervention and potential

7 for use in a future trial. Patient selection for such interventions may be important. A recent

8 multicentre randomized controlled study reported that patients more likely to respond to

9 physical activity coaching interventions were those patients with better preserved functional

10 capacity [57]. Some of our patient population were perhaps too frail to benefit maximally

11 from the proposed PAI.

Furthermore, the assessment of fidelity demonstrated that the intervention was

delivered as planned. Overall fidelity was good but an improvement could be to ensure that all providers are certified to deliver the intervention, and to assess fidelity regularly throughout the intervention, not at the end as in the present trial. Additionally, our assessment of delivery only sought to assess whether a component was delivered or not, and a scale assessing the quality of delivery of each component could further demonstrate how well the intervention was delivered. The fidelity assessment methods and results will be reported in a future publication.

The estimated time to deliver the PAI to eight patients individually across 12 weeks is 60.8 (34.4) hours. The estimated time to deliver a PR programme to eight patients in a group over 6 weeks is 24 hours. The LIVELY PAI appears to takes approximately double the amount of time to deliver to eight patients compared to PR, which would result in increased costs. However, there is a large SD in the predicted length of time to deliver the PAI to eight patients, and the PAI had a higher rate of adherence which has potential for cost saving 
1 implications in the longer term. Finally, we are comparing two different models of treatment

2 for people with COPD and there are opportunities to modify the PAI to reduce costs and

3 bring them more in line with PR. For example, using an online platform linked to the activity

4 monitor whereby the steps are automatically uploaded, so that the interventionist can review

5 these before the consultation, would reduce costs. The number of face to face consultations

6 could also be decreased; qualitative data from the current trial demonstrated that some

7 participants felt they could have transitioned to this earlier. It has been suggested that much

8 of the coaching could be done using a telemedicine approach $[57,58]$, although not all trials

9 were equally successful [59]. Furthermore delivery in a group setting while retaining

10 individual setting of step goals could decrease the time taken to deliver the PAI, delivery of

11 education in a group setting could also be adopted in a future trial. The PAI in this study

12 included management of breathlessness, and advice regarding inhalers and the management

13 of an exacerbation. Patients were also given the LWWCOPD for PR booklet which includes

14 information on the same education topics that are delivered in PR, Additional education and

15 other components could be embedded in a future trial for example, additional education

16 topics could be added to mirror those included in PR, and/or patients could attend group

17 education sessions.

18 The underpinning rationale for this study was that PR may not be suitable for all

19 patients with COPD; this may also be true for the PAI, as evidenced by the large standard

20 deviation in step count and MVPA for both groups. Figure 3 also demonstrates that some

21 participants in the PAI were more responsive to this intervention that others. These results

22 suggest that there are patient phenotypes which may be more responsive to a PAI or to PR.

23 The population in the current study were of moderate disease severity and according to the

24 CAT scores, their COPD had a severe impact on their quality of life. Characteristics such as

25 disease severity have been reported to have an impact on daily physical activity levels [60] 
1 and patients with better preserved functional status are reported to have had better outcomes

2 in a remote telecoaching PAI [57]. Furthermore patient preferences for the type of activity

3 may also have an impact on outcome for example the results of the qualitative component of

4 the current study found that the group setting was a both a facilitator and barrier for

5 participants in the PR group. Booth et al. [61] reported that individuals have clear preferences

6 for the types of activity they wish to engage in. Therefore, patient selection in terms of

7 disease severity, functional status and individual preference may be important to consider in a

8 future trial. Further research is required to establish phenotypes and preferences to better

9 stratify patient care and optimise outcome.

11 Strengths and limitations

A key strength of this study is that it provides important feasibility data regarding screening, recruitment, delivery of the intervention and data analysis for a future trial. The PR was delivered as part of usual care. The results of the PR group in relation to exercise capacity and quality of life are not in line with expected outcomes [1] and may in part be explained by the proportion of non adherherers/dropouts in this group.; a future trial should consider ensuring all PR programmes are optimised prior to study implementation through to study completion and quality assurance measures for PR should be included as part of usual care.

A future trial would also need to include a cost effectiveness limb as well as

21 additional data beyond the EQ5D5L to allow for a full health economic appraisal.

22 Furthermore in the current intervention the measurement of step count alone as an indicator of physical activity, although central to a number of tasks does, not take into account all the components necessary to execute all activities of daily living. 


\section{Conclusion}

3 All applicable NIHR criteria for the success of a feasibility study were met with important

4 learning and information regarding recruitment, eligibility, outcome measures and the sample

5 size for a future study identified. The mixed methods design has enriched the data and

6 exploring patients' views and satisfaction has helped complement and verify the quantitative

7 findings. The LIVELY PAI appears to be effective in improving step counts in people with

8 COPD, feasible to deliver and had good fidelity. This study provides key information to

9 inform a future randomised controlled trial in physical activity.

\section{Acknowledgments}

12 The study was funded by the Northern Ireland Chest Heart and Stroke (NICHS). PhD student (O'Shea

13 O), was funded by the Department of Employment and Learning. The study was sponsored by the

14 Ulster University and the Western and Belfast Health and Social Care Trusts. The study was

15 supported by the Northern Ireland Clinical Research Network (NICRN) Respiratory Health interest 16 group, thank you specifically to Dr Denise Cosgrove, Adrian McDonald and Dr. Catherine Hanratty.

17 Thank you to our patient representative (JH) for their valuable input to the study

19 Declaration of interest

20 The authors have no conflicts of interest to declare.

\section{References}

22 1.McCarthy B, Casey D, Devane D, Murphy K, Murphy E, Lacasse Y. Pulmonary

23 rehabilitation for chronic obstructive pulmonary disease. Cochrane Database of Syst

$24 \quad$ Rev 2015; 2:1-173. 
1 2.Troosters T, Gosselink R, Janssens W, Decramer M. Exercise training and pulmonary rehabilitation: New insights and remaining challenges. Eur Respir Rev 2010; 19(115):24-29.

3. Watz H, Pitta F, Rochester CL, Garcia-Aymerich J, ZuWallack R, Troosters T, et al. An official European Respiratory Society statement on physical activity in COPD. Eur Respir J. 2014; 44(6):1521-37.

4. Bolton CE, Bevan-Smith EF, Blakey JD, Crowe P, Elkin SL, Garrod R et al. British Thoracic Society guideline on pulmonary rehabilitation in adults: accredited by NICE. Thorax 2013 Sep; 68(Suppl 2):ii1-ii30.

5. Steiner MC, Roberts MC, Lowe D, Welham S, Searle L, Skipper E et al. National Chronic Obstructive Pulmonary Disease (COPD) Audit Programme: Clinical audit of Pulmonary Rehabilitation services in England and Wales 2015. Healthcare Quality Improvement Partnership. 2016.

6. Jones SE, Green SA, Clark AL, Dickson MJ, Nolan AM, Moloney C et al. Pulmonary rehabilitation following hospitalisation for acute exacerbation of COPD: referrals, uptake and adherence. Thorax. 2014; 69: 181-2.

7. Rochester CL, Vogiatzis I, Holland AE, Lareau SC, Marciniuk DD, Puhan MA et al. Am J Respir Crit Care Med. 2015; 192 (11): 1373-1386.

8. Min-Lee I and Skerrett PJ. Physical activity and all-cause mortality: what is the doseresponse relation? Med. Sci. Sports Exerc. 2001; 33(6): S459-S471.

9. McDonough SM, A. Tully MA, Boyd A, O’Connor SR, Kerr DP, O’Neill SM, et al. Pedometer-driven Walking for Chronic Low Back Pain A Feasibility Randomized Controlled Trial. Clin J Pain. 2013; 29(11): 972-981.

10. Wilson JJ, O’Neill B, Collins EG Bradley J. Interventions to Increase Physical Activity in Patients with COPD: A Comprehensive Review. COPD 2014: 00:1-12.

11. Behnke M, Wewel AR, Kirsten D, Joreres, RA, Magnussen, H. Exercise training raises daily activity in stronger than predicted from exercise capacity in patients with COPD. Resp Med. 2005; 99(6):711-717.

12. Breyer M, Breyer-Kohansal R, Funk G, Dornhofer N, Spruit MA, Wouters EF, et al. Nordic Walking improves daily physical activities in COPD: a randomised controlled trial. Resp Res. 2010; 11 (112). 
13. Moy ML, Janney AW, Nguyen HQ, Matthess KR, Cohen M, Garshick E, et al. Use of pedometer and Internet-mediated walking program inpatients with chronic obstructive pulmonary disease. J Rehabil Res Dev. 2010; 47(5): 485-496.

14. Hospes G, Bossenbroek L, ten Hacken NH, van Hengel P, de Greef MH. Enhancement of daily physical activity increases physical fi tness of outclinic COPD patients: results of an exercise counseling program. Patient Educ Couns 2009; 75(2):274-278.

15. Altenburg WA, ten Hacken NH, Bossenbroek L, Kerstjens HA, de Greef MH, Wempe JB. Short- and long-term effects of a physical activity counselling programme in COPD: a randomized controlled trial. Respir Med. 2015; 109(1):112-21.

16. Tabak M, Vollenbroek-Hutten MM, van der Valk PD, van der Palen J, Hermens HJ. A telerehabilitation intervention for patients with Chronic Obstructive Pulmonary Disease: a randomized controlled pilot trial. Clin Rehabil 2013; 28(6):582-591.

17. Steele BG, Belza B, Cain KC, Coppersmith J, Lakshminarayan S, Howard J, Haselkorn JK. A randomized clinical trial of an activity and exercise adherence intervention in chronic pulmonary disease. Arch Phys Med Rehabil. 2008; 89(3):404-412.

18. National Institute for Health Research Success Criteria for a feasibility trial [internet]. Cited 2017 May 5. Available from: http://www.nets.nihr.ac.uk/glossary

19. Craig P, Dieppe P, MacIntyre S, Michie S, Nazareth I, Petticrew M. Medical Research Councol [internet]. 2006 [Cited 2017 May 20] Developing and evaluating complex interventions: new guidance. Available from: www.mrc.ac.uk/complexinterventionsguidance

20. Thabane L, Ma J, Chu R, Cheng J, Ismaila A, Rios LP et al. A tutorial on pilot studies: the what, why and how. BMC Med Res Method 2010; 10:1.

21. Lancaster G. Pilot and feasibility studies come of age! Pilot Feasibility Stud 2015; 1:1.

22. O'Cathain A, Hoddinott P, Lewin S, Thomas KJ, Young B, Adamson J et al.Maximising the impact of qualitative research in feasibility studies for randomised controlled trials: guidance for researchers. Pilot Feasibility Stud 2015; 1:32.

23. Hoffman TC, Glasziou PP, Milne R, Moher D, Altman DG, Barbour V et al. Better reporting of interventions: template for intervention description and replication (TIDieR) checklist and guide. BMJ 2014; 348:1687.

24. Schulz KF, Altman DG, Moher D, CONSORT Group. CONSORT 2010 statement: updated guidelines for reporting parallel group randomized trials. Ann Intern Med. 2010;152:726-32. 
25. Sim $\mathbf{J}$ and Lewis $\mathrm{M}$. The size of a pilot study for a clinical trial should be calculated in relation to considerations of precision and efficiency. J Clin Epidemiol 2012; 65:301308.

26. Michie S, Atkins L, West R. The Behaviour Change Wheel: A Guide to Designing Interventions, First Edition. Silverback Publishing, Great Britain. 2014.

27. Michie S, Richardson M, Johnston M, Abraham C, Francis J, Hardeman W, Eccles MP, Cane J, Wood CE. The behavior change technique Taxonomy (v1) of 93 Hierarchically clustered techniques: Building an international consensus for the reporting of behavior change interventions. Ann Behav Med 2013; 46:81-95.

28. Cosgrove D, MacMahon J, Bourbeau J, Bradley JM, O'Neill B. Facilitating education in pulmonary rehabilitation using the living well with COPD programme for pulmonary rehabilitation: a process evaluation. BMC Pulm Med. 2013;13:50.

29. Williams S, Baxter N, Buxton M, Harrison A, Holmes S, Hughes E et al. IMPRESS Guide to Pulmonary Rehabilitation British Thoracic Society Reports. 2011; 3(2).

30. Rabinovich RA, Louvaris Z, Raste Y, Langer D, Van Remoortel H, Giavedoni S,et al. Validity of physical activity monitors during daily life in patients with COPD. Eur Respir J. 2013; 42(5):1205-15.

31. Schneider PL, Crouter S, Basset DR. Pedometer measures of free living physical activity: comparison of 13 models. Med Sci Sports Exerc. 2004; 36(2):331-5.

32. Craig CL, Marshall AL, Sjostrom M, Bauman AE, Booth ML, Ainsworth BE et al. International Physical Activity Questionnaire:12-Country Reliability and Validity. Med Sci Sports Exerc. 2003; 35(8):1381-95.

33. Singh SJ, Morgan MDL, A.E. Hardman AE, Rowe C, Bardsley PA. Comparison of oxygen uptake during a conventional treadmill test and the shuttle walking test in chronic airflow limitation. Eur Respir J. 1994; 7: 2016-2020.

34. Jones PW, Harding G, Berry P, Wiklund I, Chen WH, Kline Leidy N. Development and first validation of the COPD Assessment Test. Eur Respir J 2009;34:648-654.

35. Briggs AH, Glick HA, Lozano-Ortega G, Spencer M, Calverley PMA, Jonese PW et al. Is treatment with ICS and LABA cost-effective for COPD? Multinational economic analysis of the TORCH study. Eur Respir J 2010; 35: $532-$ 539.

36. Perry M. Activity Monitoring and low back pain. Chapter 1. Awarded PhD 2010 from University of Otago. 
1 37. Marcus $\mathrm{BH}$ and Forsyth LH. Motivating people to be physically active. $2^{\text {nd }}$ edition. Human Kinetics: United States of America; 2009.

38. Borrelli B. The Assessment, Monitoring, and Enhancement of Treatment Fidelity in Public Health Clinical Trails. J Public Health Dent. 2011;71 (1): 1-21.

39. Bellg A, Borrelli B, Resnick B, Hecht J, Minicucci D, Ory M, et al. Enhancing treatment fidelity in health behavior change studies: best practices and recommendations from the NIH Behavior Change Consortium. Health Psychol. 2004; 23:443-51.

40. Byron B and Rowe DA. Measuring free-living physical activity in COPD patients: Deriving methodology standards for clinical trials through a review of research studies. Contemp Clin Trials. 2016; 47:172-184.

41. Matthiessen J, Raustorp A, Knudson V. Reduction in pedometer-determined physical activity in the adult Danish population from 2007 to 2012. Scand J Public Health 2015; 1-9.

42. King, N. Template analysis', in G.Symon and C.Cassell (eds.) Qualitative Methods and Analysis in Organizational Research. London: Sage. 1998

43. GOLD [internet] Cited 2017 April 04. Available from: http://goldcopd.org/wpcontent/uploads/2016/12/wms-GOLD-2017-Pocket-Guide.pdf

44. Demeyer H, Burtin C, Hornikx M, Camillo CA, Van Remoortel H, Langer D et al. The Minimal Important Difference in Physical Activity in Patients with COPD. PLoS ONE 2016; 11(4):1-11.

45. Chaplin E, Hewitt S, Apps L, Bankart J, Pulikottil-Jacob R, Boyce S et al. Interactive web-based pulmonary rehabilitation programme: a randomised controlled feasibility trial. BMJ Open 2017;7:e013682.

46. Varga J, Porszasz J, Boda K, Richard Casaburi R, Somfay A. Supervised high intensity continuous and interval training vs. self-paced training in COPD. Respir Med 2007; 101: 2297-2304.

47. Berry MJ, Rejeski WJ,. Adair NE, Ettinger WH, Zaccaro DJ, Sevick MA. A Randomized, Controlled Trial Comparing Long-term and Short-term Exercise in Patients With Chronic Obstructive Pulmonary Disease. J Cardiopulm Rehabil 2003;23:60-68.

48. Horton EJ, Mitchell KE, Johnson-Warrington V, Apps LD, Sewell L, Morgan M et al. Comparison of a structured home-based rehabilitation programme with conventional 
supervised pulmonary rehabilitation: a randomised non-inferiority trial. Thorax $2017 ; 0: 1-8$

49. Main E. Airway clearance research in CF: the 'perfect storm' of strong preference and effortful participation in long-term, non-blinded studies. Thorax 2013;68:701-702

50. O’Neill B, McKevitt AM, Sara Rafferty S, Bradley JM, Johnston D, Bradbury I et al. A Comparison of Twice- Versus Once-Weekly Supervision During Pulmonary Rehabilitation in Chronic Obstructive Pulmonary Disease. Arch Phys Med Rehabil. $2008 ; 88$.

51. van Remoortel H, Raste Y., Louvaris Z, Giavedoni S, Burtin C, Langer D. Validity of Six Activity Monitors in Chronic Obstructive Pulmonary Disease: A Comparison with Indirect Calorimetry. PLoS ONE 2012;7(6) e39198.

52.Vooijs M, Alpay LA, Snoeck-Stroband JB, Beerthuizen T, Siemonsma P, Abbink JJ, Validity and Usability of Low-Cost Accelerometers for Internet-Based SelfMonitoring of Physical Activity in Patients With Chronic Obstructive Pulmonary Disease. Interact J Med Res 2014; 3(4):e14.

53. O’Neill B, McDonough SM, Wilson JJ, Bradbury I, Hayes K, Kirk A. Comparing accelerometer, pedometer and a questionnaire for measuring physical activity in bronchiectasis: a validity and feasibility study? Respir Res 2017;18:16.

54. Kinnunen TI, Tennant PWG, McParlin C, Poston L, Robson SC, Bell R. Agreement between pedometer and accelerometer in measuring physical activity in overweight and obese pregnant women. BMC Public Health. 2011;11:501. doi:10.1186/14712458-11-501.

55. Harris TJ, Owen CG, Victor CR, Adams R, Ekelund U, Cook DG. A comparison of questionnaire, accelerometer, and pedometer: measures in older people. Med Sci Sports Exerc. 2009;41:1392-402.

56. Paxton RJ, Forster JE, Miller MJ, Gerron KL, Stevens-Lapsley JE, Christiansen CL. A feasibility study for improved physical activity after total knee arthroplasty. J Ageing Phys Act 2017; 0 (0): 1-21.

57. Demeyer H, Louvaris Z, Frei A, Rabinovich RA, de Jong C, Gimeno-Santos E, et al. Physical activity is increased by a 12 -week semiautomated telecoaching programme in patients with COPD: a multicentre randomised controlled trial. Thorax 2017;72:415-423. 
58. Moy ML, Collins RJ, Martinez CH, Kadri R, Roman P, Holleman RG, et al. An Internet-Mediated Pedometer-Based Program Improves Health-Related Quality-ofLife Domains and Daily Step Counts in COPD A Randomized Controlled Trial. Chest 2015; 148(1): $128-137$

59. Vorrink SNW, Kort HSM, Troosters T, Zanen P and Lammers JWJ. Efficacy of an mHealth intervention to stimulate physical activity in COPD patients after pulmonary rehabilitation. Eur Respir J 2016; 48: 1019-102

60. Clarenbach CF, Sievi NA, Haile SR, Brack T, Brutsche MH, Fewy M, et al. Determinants of annual change in physical activity in COPD. Respirology 2017 doi: 10.1111/resp.13035

61. Booth ML, Bauman A, Owen N, Gore CJ. Physical Activity Preferences, Preferred Sources of Assistance, and Perceived Barriers to Increased Activity among Physically Inactive Australians. Prev Med, 1997; 26:131-137.

\section{On line E Supplement}

- eTable 1 TIDieR checklist [16]: Assessment of reporting in the LIVELY COPD project

- eTable 2 The assessment and results of treatment fidelity in the LIVELY COPD project with the Borrelli (2011) checklist

- eTable 3 Examples of how weekly step goals were set and of outcome goals

- eTable 4 Summary of semi structured interview schedule

- eTable 5 Screening data, reasons for exclusion from the LIVELY COPD project.

- eTable 6 Baseline demographics and characteristics of participants.

- eTable 7 Available outcome measures at each time point and reasons for any missing data. 
- eTable 8 Participant physical activity outcomes (Actigraph, sealed pedometer, IPAQ and GROC), ISWT, CAT and EQ5D5L for the PAI group and PR group at baseline and post intervention (mean (SD)[CI]).

4 


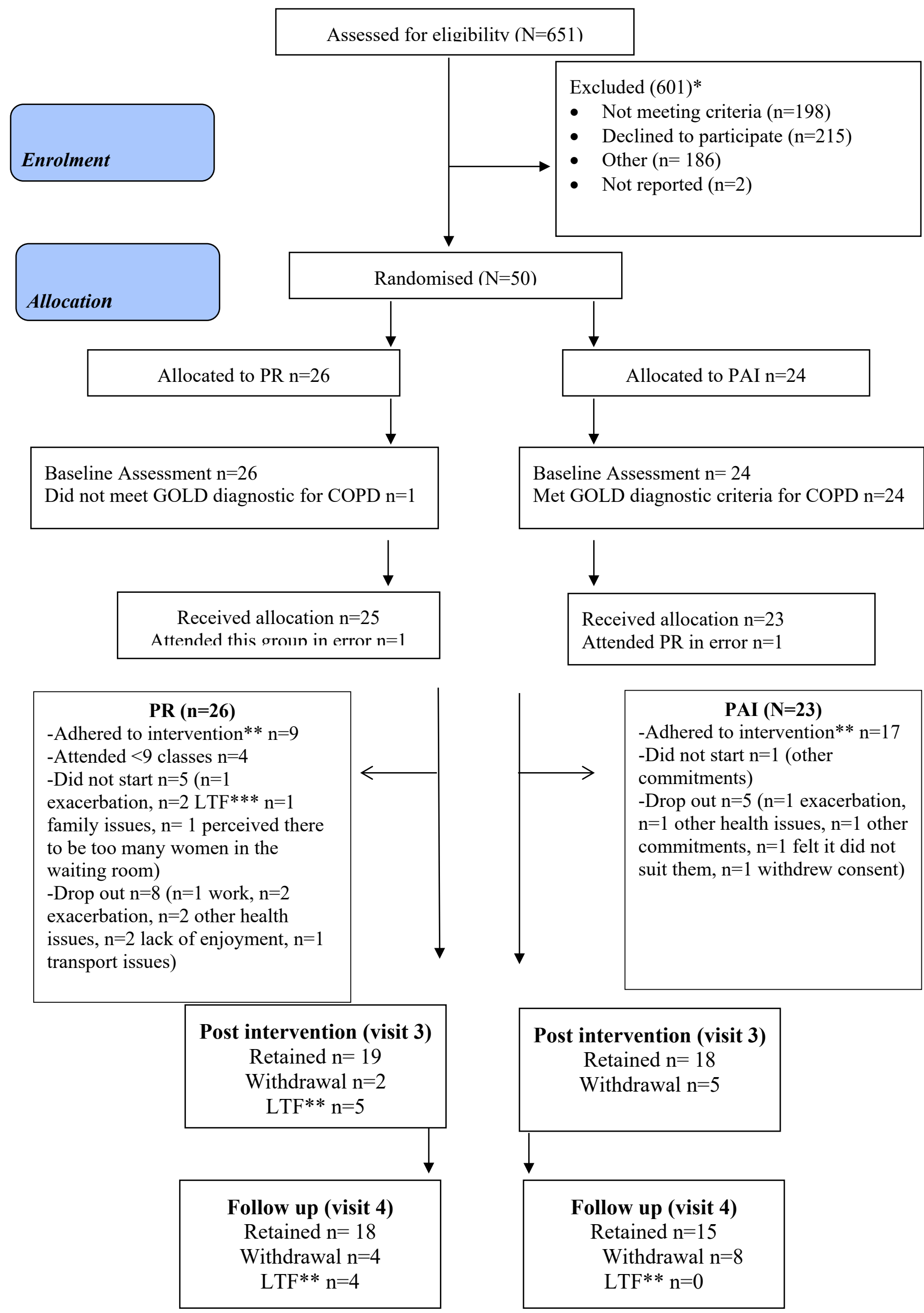

Figure 1 CONSORT Flow of participants through the study and adherence to the PAI and PR [24] * reasons for exclusion are in eTable $5 * *$ Adherence set at $75 \%$ (attending $9 / 12$ classes/consultations) [22], ***LTF Lost to follow up 


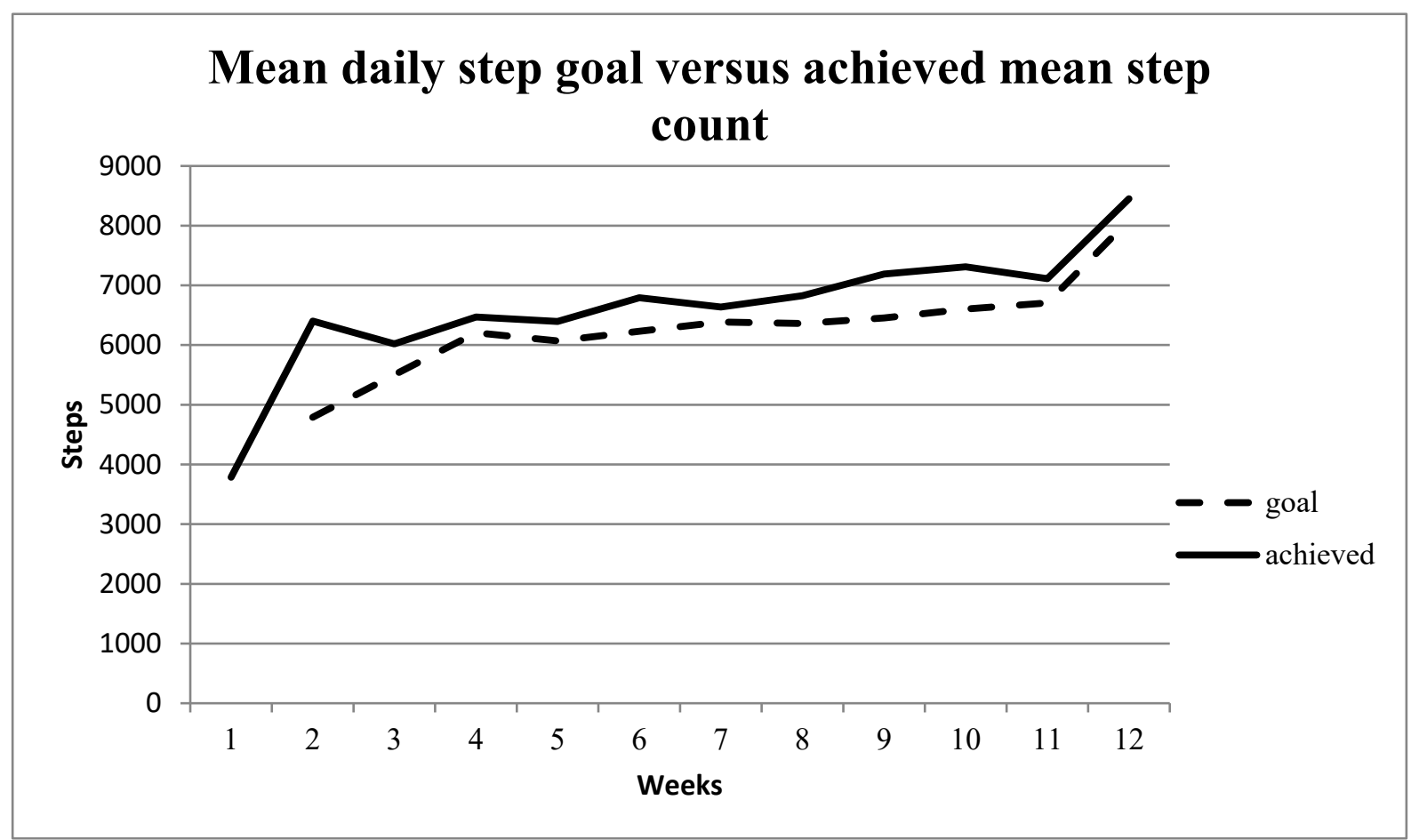

Figure 2 Mean daily step count goal compared to the step count achieved across the 12 PAI [numbers of participants providing step count data at each time point varies due to attendance and withdrawals; familiarisation. Week $1, n=21$; Week $2, n=18 \mathrm{~W}$ week 3, n=19; Week 4, n=18; Week 5, n=17; Week 6, n=18; Week 7, $\mathrm{n}=18$; Week 8, $\mathrm{n}=17$; Week 9, $\mathrm{n}=17$; Week 10, $\mathrm{n}=17$; Week 11, $\mathrm{n}=16$; Week 12, $\mathrm{n}=3$.] 


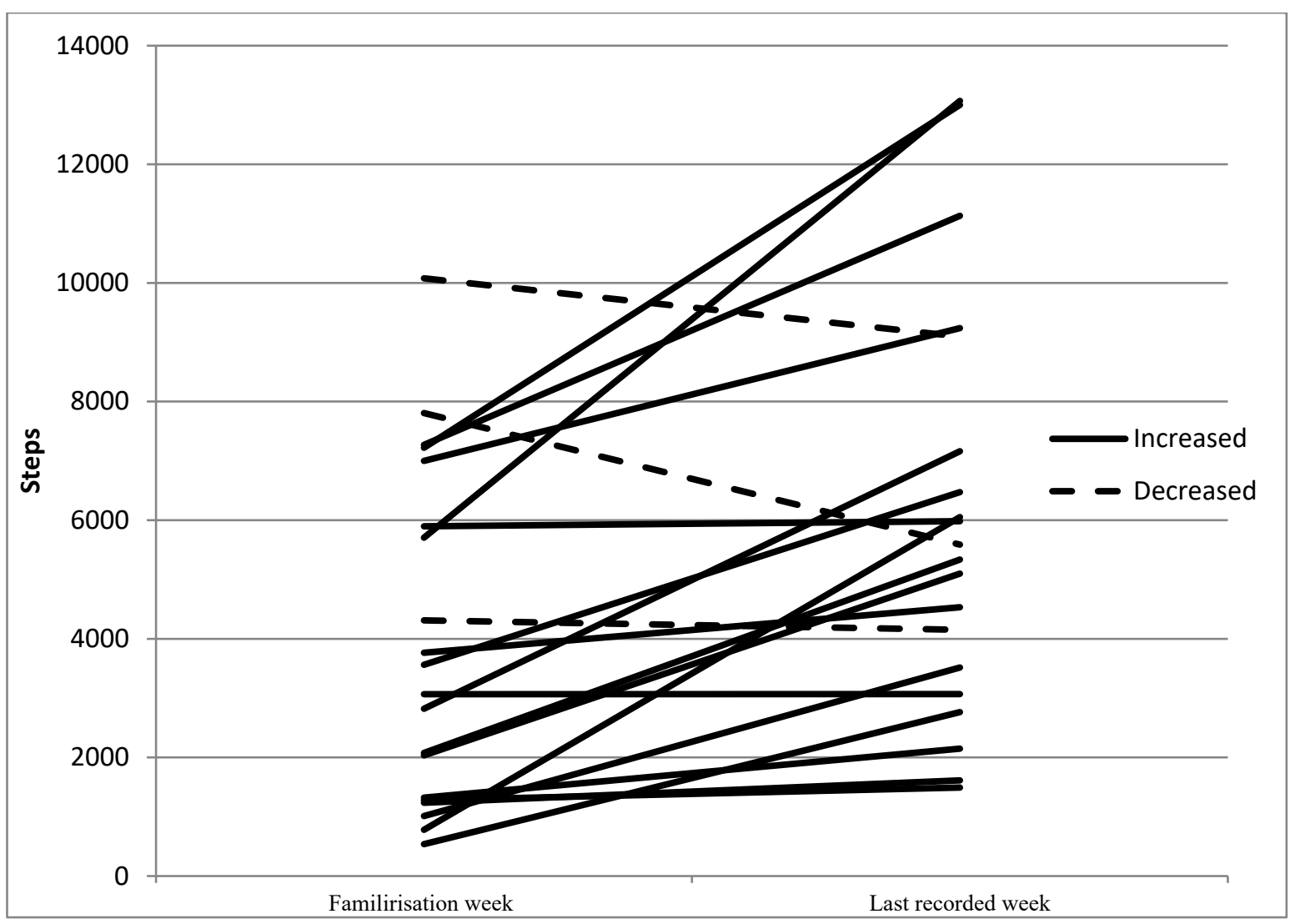

Figure 3 Difference between the mean daily step count for the familiarisation week and the last available mean daily step count recorded with the unsealed pedometer for all participants who provided a step count at two time points $n=20$ in the PAI 


\section{E supplement}

\section{On line E Suppl Contents}

- eTable 1 TIDieR checklist [16]: Assessment of reporting in the LIVELY COPD project

- eTable 2 The assessment and results of treatment fidelity in the LIVELY COPD project with the Borrelli (2011) checklist

- eTable 3 Examples of how weekly step goals were set and of outcome goals

- eTable 4 Summary of semi structured interview schedule

- eTable 5 Screening data, reasons for exclusion from the LIVELY COPD project.

- eTable 6 Baseline demographics and characteristics of participants.

- eTable 7 Available outcome measures at each time point and reasons for any missing data.

- eTable 8 Participant physical activity outcomes (Actigraph, sealed pedometer, IPAQ and GROC), ISWT, CAT and EQ5D5L for the PAI group and PR group at baseline and post intervention (mean (SD)[CI]). 
eTable 1 TIDieR checklist (16): Assessment of reporting in the LIVELY COPD project

\begin{tabular}{|c|c|}
\hline TIDieR Checklist & Reported \\
\hline 1.Brief name: provide a name or a phrase that describes the intervention & $\checkmark$ \\
\hline $\begin{array}{l}\text { 2.Why: Describe any rationale theory or goal of elements essential to } \\
\text { the intervention }\end{array}$ & $\checkmark$ \\
\hline $\begin{array}{l}\text { 3. What (materials): describe any physical or informational materials } \\
\text { used in the intervention including those provided to participants or used } \\
\text { in the intervention or in training of intervention providers. Provide } \\
\text { information on where the materials can be accessed*. }\end{array}$ & $\checkmark$ \\
\hline $\begin{array}{l}\text { 4. What (procedures): describe each of the procedures, activities and or } \\
\text { processes used in the intervention including any enabling or support } \\
\text { activities. }\end{array}$ & $\checkmark$ \\
\hline $\begin{array}{l}\text { 5. Who provided: for each category of intervention provider, describe } \\
\text { their expertise background and specific training given. }\end{array}$ & $\checkmark$ \\
\hline $\begin{array}{l}\text { 6. How: Describe the modes of delivery such as face to face or by some } \\
\text { other mechanism, such as internet/telephone) of the intervention and } \\
\text { whether it was provided individually or in a group. }\end{array}$ & $\checkmark$ \\
\hline $\begin{array}{l}\text { 7. Where: Describe the type(s) of location(s) where the intervention } \\
\text { occurred including any necessary infrastructure or relevant features }\end{array}$ & $\checkmark$ \\
\hline $\begin{array}{l}\text { 8. When and how much: Describe the number of times the intervention } \\
\text { was delivered and over what period of time including the number of } \\
\text { sessions, their schedule and their duration, intensity and dose }\end{array}$ & $\checkmark$ \\
\hline
\end{tabular}




\begin{tabular}{|l|l|}
\hline $\begin{array}{l}\text { 9. Tailoring: If the intervention was planned to be personalised, titrated } \\
\text { or adapted then describe what, why when and how }\end{array}$ & $\checkmark$ \\
\hline 10. Modifications: If the intervention was modified during the course of & N/A \\
the study describe the changes (What, why, when and how) & \\
\hline $\begin{array}{l}\text { 11. How well (planned): if the intervention adherence or fidelity was } \\
\text { assessed, describe how and by whom and if any strategies were used to }\end{array}$ & $\checkmark$ \\
maintain or improve fidelity describe them. & \\
\hline 12. How well (actual): If the intervention adherence or fidelity was & $\checkmark$ \\
assessed, describe the extent to which the intervention was delivered as & \\
planned & \\
\hline
\end{tabular}

*materials can be accessed by contacting b.oneill@ulster.ac.uk 
eTable 2 The assessment and results of treatment fidelity in the LIVELY COPD project with the Borrelli (2011) checklist

\begin{tabular}{|c|c|}
\hline $\begin{array}{l}\text { Treatment } \\
\text { fidelity } \\
\text { domain }\end{array}$ & The assessment and results of treatment fidelity in the LIVELY COPD project \\
\hline $\begin{array}{l}\text { Study } \\
\text { design }\end{array}$ & $\begin{array}{l}\text {-The PAI was planned to take } 12 \text { weeks; delivery over } 14 \text { weeks was allowed to } \\
\text { accommodate for missed consultations. The face to face consultations were planned } \\
\text { to take up to one hour with telephone consultations to take } 10-20 \text { minutes. } \\
\text {-PR sites were contacted prior to the intervention starting, and mid way through the } \\
\text { study to ensure they were still adhering to the BTS guidelines (4) i.e. twice weekly } \\
\text { sessions for } 6 \text { weeks. } \\
\text {-Specific provider credentials were set out from the beginning; any nurses or } \\
\text { physiotherapists working in the Northern Irish Clinical Research who had } \\
\text { experience with respiratory patients were sought. Three providers ( } 2 \\
\text { physiotherapists and } 1 \text { nurse) were trained to deliver the intervention. } \\
\text {-The LIVELY intervention was based upon recommendations from the current } \\
\text { physical activity guidelines, influences from the stages of changes and the COM-B } \\
\text { model was considered. The study team had expert knowledge in research, }\end{array}$ \\
\hline
\end{tabular}




\begin{tabular}{|c|c|}
\hline & $\begin{array}{l}\text { behaviour change, COPD and physical activity. The measures used to assess the } \\
\text { efficacy of the PAI in comparison to PR were chosen as they reflected the } \\
\text { hypothesis and the mechanisms of action of the intervention. } \\
\text {-Multiple providers were trained to deliver the intervention; participants were } \\
\text { recruited across multiple sites and } n=3 \text { researchers were trained in outcome measure } \\
\text { assessment. }\end{array}$ \\
\hline $\begin{array}{l}\text { Training } \\
\text { providers }\end{array}$ & $\begin{array}{l}\text {-A plan for training was set out; the first three and fifth training sessions were } \\
\text { conducted as planned, training day } 4 \text { was conducted } 2 \text { months early, as due to study } \\
\text { through put additional training was required early. It was planned that all providers } \\
\text { would receive the standard training; due to unforeseen circumstances one provider } \\
\text { could not attend all training days; but received one-one training to compensate for } \\
\text { these missed days. } \\
\text {-Skill acquisition was assessed informally during the training using case studies. } \\
\text { Regular training and a mentorship programme ensured there was no drift in skill. } \\
\text { For the mentorship programme providers had contact with an experienced member } \\
\text { of the research team before and after each consultation. } \\
\text {-The training included theory, practical components, case scenarios, and group work } \\
\text { to help support different training needs. A feedback questionnaire was completed by } \\
\text { the providers at approximately midway to assess if they felt the training took into } \\
\text { account their different education and experience and learning styles; feedback was } \\
\text { positive. }\end{array}$ \\
\hline
\end{tabular}




\begin{tabular}{|c|c|}
\hline treatment & $\begin{array}{l}\text {-The mentorship programme helped to ensure that the content dose was delivered as } \\
\text { specified. Pre consultation checklists and templates for documentation also helped } \\
\text { to ensure this. The time taken to complete the intervention was } 12.4 \text { weeks, } \\
\text { participants completed a mean (SD) } 11.8 \text { (0.6) of the } 12 \text { planned consultations. The } \\
\text { face to face consultations lasted a mean (SD) of } 49.8 \text { (8.8) minutes and telephone } \\
\text { consultations lasted } 19.5 \text { (SD } 2.8 \text { ) minutes. } \\
\text {-N=80/221 consultations ( } 36.2 \% \text { ) were recorded; delivery was assessed in n=36 } \\
\text { (16.3\%) consultations. Specific checklists were developed to assess delivery for the } \\
\text { LIVELY PAI, this checklist contained } 50 \text { items. In line with current guidelines good } \\
\text { fidelity was set at } 80 \% \text {; } n=43 / 50 \text { items were delivered with good fidelity. } \\
\text {-A treatment manual was designed specifically for the LIVELY PAI containing step diary } \\
\text { and action and coping plans. Contamination was prevented as participants did not mix } \\
\text { following randomisation. }\end{array}$ \\
\hline Receipt of & $\begin{array}{l}\text {-The LIVELY study documents were reviewed to assess how the items on the } \\
\text { Borrelli checklist (2011) were being met in the context of LIVELY and a checklist } \\
\text { developed. } \mathrm{N}=18 \text { strategies items for receipt were identified. } \\
-16.3 \% \text { of consultations were assessed for receipt. } \mathrm{N}=3 / 18 \text { items on the receipt } \\
\text { checklist were not received on } 100 \% \text { of occasions. }\end{array}$ \\
\hline $\begin{array}{l}\text { Enactment } \\
\text { of treatment } \\
\text { skills }\end{array}$ & $\begin{array}{l}\text {-The LIVELY study documents were reviewed to assess how the items on the } \\
\text { Borrelli checklist (2011) could be assessed in the context of the LIVELY PAI. Six } \\
\text { items under enactment were identified. } \\
\text { amples of how weekly step goal was set } \\
\text { checklist were not enacted on } 100 \% \text { of the time. }\end{array}$ \\
\hline
\end{tabular}




\section{Examples of how the weekly step goal was set}

\section{Example 1}

Total weekly step count for 7days from previous week

19,747

2,821

Average daily steps from previous week

Self-efficacy walk result

4,300 on $7 / 7$ days

Agreed step goal

\section{Example 2}

Total weekly step count for 7days from previous week 39,935

Average daily steps from previous week

Self-efficacy walk result

$$
8,000 \text { on } 5 / 7 \text { days }
$$

Agreed step goal

The step target for each subsequent week was agreed between the physiotherapist/nurse and the participant by referring to 1) current walking behaviour identified from the mean daily step count for the previous week calculated from the pedometer steps/walking diary, and 2) the number of steps accumulated during the 10-minute 'self-efficacy walk'. The consultations included 
discussion of current physical activity behaviour, the identification of barriers and facilitators to change, strategies to enable patients to meet walking goals and address barriers, and strategies to enhance confidence/self-efficacy around achieving goals (self-efficacy, goal setting), action and coping plans, problem solving, social support, information on the consequences of behaviour from credible sources, and maintenance and preventing relapse. Each step goal was individual to the participant and fully personalised to them. 
eTable 4 Summary of semi structured interview schedule

\begin{tabular}{|c|}
\hline Interview Schedule Questions \\
\hline How do you feel the PAI/ PRprogramme has affected your health? \\
\hline Do you think your relatives/carers/friends see a difference in you? \\
\hline $\begin{array}{l}\text { Do you think you have a good understanding of the benefits of exercise/PA for someone } \\
\text { with COPD? }\end{array}$ \\
\hline $\begin{array}{l}\text { How satisfied were you with the: } \\
\text { a. face-to-face physical activity intervention? } \\
\text { b.pulmonary rehabilitation programme? }\end{array}$ \\
\hline What suggestions if any, would you give to improve the PAI/ PR programme? \\
\hline $\begin{array}{l}\text { How involved did you feel in shaping the PAI/ PR programme, do you feel your level of } \\
\text { fitness/ability was considered? }\end{array}$ \\
\hline How easy did you find it to adhere to the PAI/ PR programme? \\
\hline Have you ever done pulmonary rehab before? \\
\hline This research wanted to test how the PAI/PR programme affected your health. \\
\hline $\begin{array}{l}\text { During the information collecting sessions with the researcher you wore two activity } \\
\text { monitors for seven days at home, did a number of questionnaires and completed a walk } \\
\text { test. How did you find these? }\end{array}$ \\
\hline $\begin{array}{l}\text { How confident are you that you could continue to exercise or do physical activity on your } \\
\text { own now that the programme has finished? }\end{array}$ \\
\hline $\begin{array}{l}\text { Would you recommend the PAI/ PR programme to anyone else who has COPD? (optional } \\
\text { question) }\end{array}$ \\
\hline $\begin{array}{l}\text { Is there anything else that you would like to add regarding your experiences of taking part } \\
\text { in the study? }\end{array}$ \\
\hline
\end{tabular}


eTable 5 - Screening data, reasons for exclusion from the LIVELY study in COPD

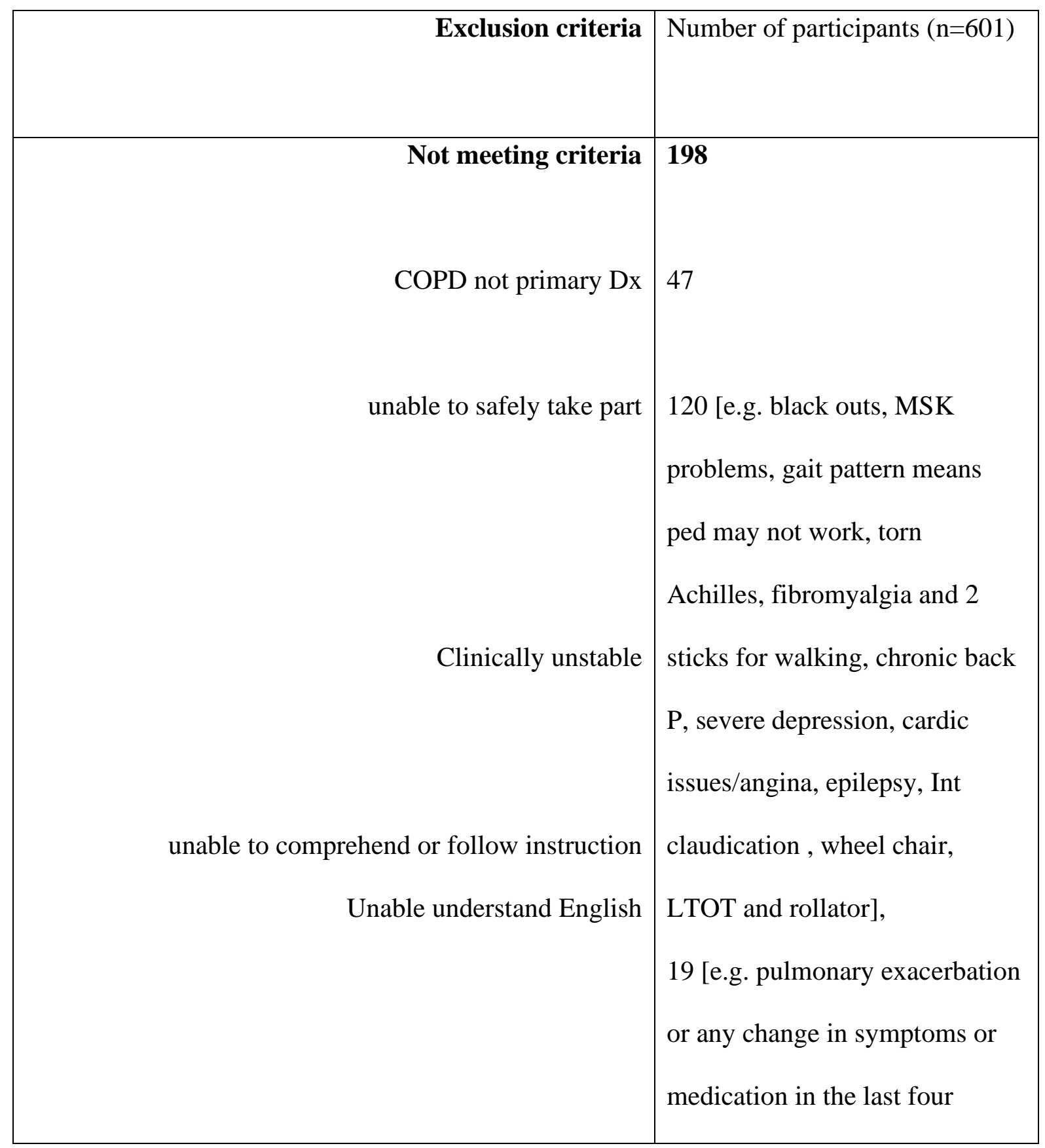




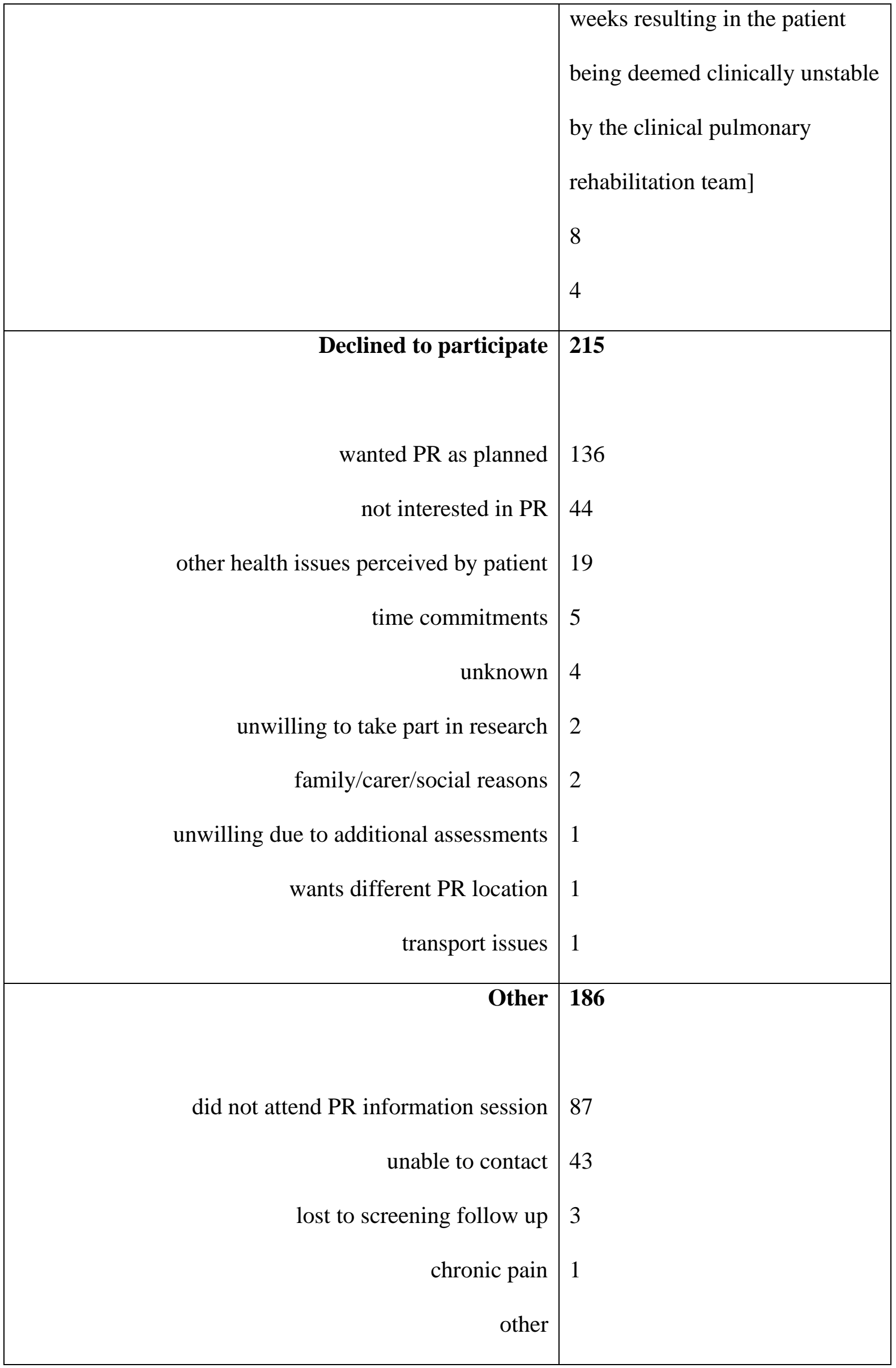




\begin{tabular}{|r|l|}
\hline deceased & HSC [e.g. awaiting lung Sx, wrong \\
referred to incorrect PR site & PR] \\
Did Not Attend Outcomes Assessment & 2 \\
Recruitment target reached for that PR site & 4 \\
& 4 \\
\hline Non reported & 2 \\
\hline Total Excluded & $\mathbf{6 0 1}$ \\
\hline
\end{tabular}

eTable 6 Baseline demographics and characteristics of participants

\begin{tabular}{|l|l|l|l|}
\hline \multicolumn{1}{|c|}{$\begin{array}{c}\text { Baseline Demographic } \\
\text { Characteristics }\end{array}$} & $\begin{array}{l}\text { Whole } \\
\text { population } \\
\text { N=49 }\end{array}$ & Physical Activity & Pulmonary \\
\hline $\begin{array}{l}\text { Age (years) } \\
\text { Mean ( } \pm \text { SD) }\end{array}$ & $64.3(8.6)$ & $61.1(8.5)$ & Rehabilitation N=26 \\
\hline Gender (m:f) & $24: 25$ & $13: 10$ & $67.2(7.8)$ \\
\hline BMI (kg/m ${ }^{2)}$ & $27.8(7.0)$ & $27.3(7.4)$ & $11: 15$ \\
\hline Medicine use & $7.9(3.8)$ & $7.2(3.6)$ & $28.4(6.8)$ \\
Respiratory medication only & $3.3(0.9)$ & $3.5(0.8)$ & $3.1(0.9)$ \\
\hline Co-morbidities & & & \\
\hline$=2$ & $\mathrm{~N}=29$ & $\mathrm{~N}=9$ & \\
\hline
\end{tabular}




\begin{tabular}{|c|c|c|c|}
\hline \multicolumn{4}{|l|}{ Occupation (Freq) } \\
\hline Retired & 30 & 12 & 18 \\
\hline Unemployed & 9 & 7 & 2 \\
\hline Employed & 9 & 4 & 5 \\
\hline Other & 1 & 0 & 1 \\
\hline \multicolumn{4}{|l|}{ Living arrangements (Freq) } \\
\hline Living alone & 17 & 11 & 6 \\
\hline Living with family & 32 & 12 & 20 \\
\hline $\mathrm{FEV}_{1} \mathrm{~L} / \mathrm{min}$ Mean $( \pm \mathrm{SD})$ & $1.4(0.6)$ & $1.4(0.6)$ & $1.4(0.6)$ \\
\hline \multicolumn{4}{|l|}{ GOLD classification } \\
\hline Mild & 8 & 3 & 5 \\
\hline Moderate & 18 & 7 & 11 \\
\hline Severe & 18 & 11 & 7 \\
\hline Very severe & 5 & 2 & 3 \\
\hline $\begin{array}{l}\text { CAT }(0-40 ; \text { a higher score } \\
\text { indicates a higher severity })\end{array}$ & $21.1(7.5)$ & $23.8(6.9)$ & $18.7(7.3)$ \\
\hline \multicolumn{4}{|l|}{ CAT severity (frequency) } \\
\hline V high (>30) & 6 & 5 & 1 \\
\hline High $(>20)$ & 22 & 10 & 12 \\
\hline Medium (10-20) & 18 & 8 & 10 \\
\hline Low $(<10)$ & 3 & 0 & 3 \\
\hline \multicolumn{4}{|c|}{$\begin{array}{l}\text { Longterm Oxygen therapy use } \\
\text { (Frequency) }\end{array}$} \\
\hline Yes & 6 & 3 & 3 \\
\hline No & 43 & 20 & 23 \\
\hline \multicolumn{4}{|l|}{ Smoking history } \\
\hline Never & 2 & 0 & 2 \\
\hline Ex & 37 & 17 & 20 \\
\hline Current & 10 & 6 & 4 \\
\hline
\end{tabular}




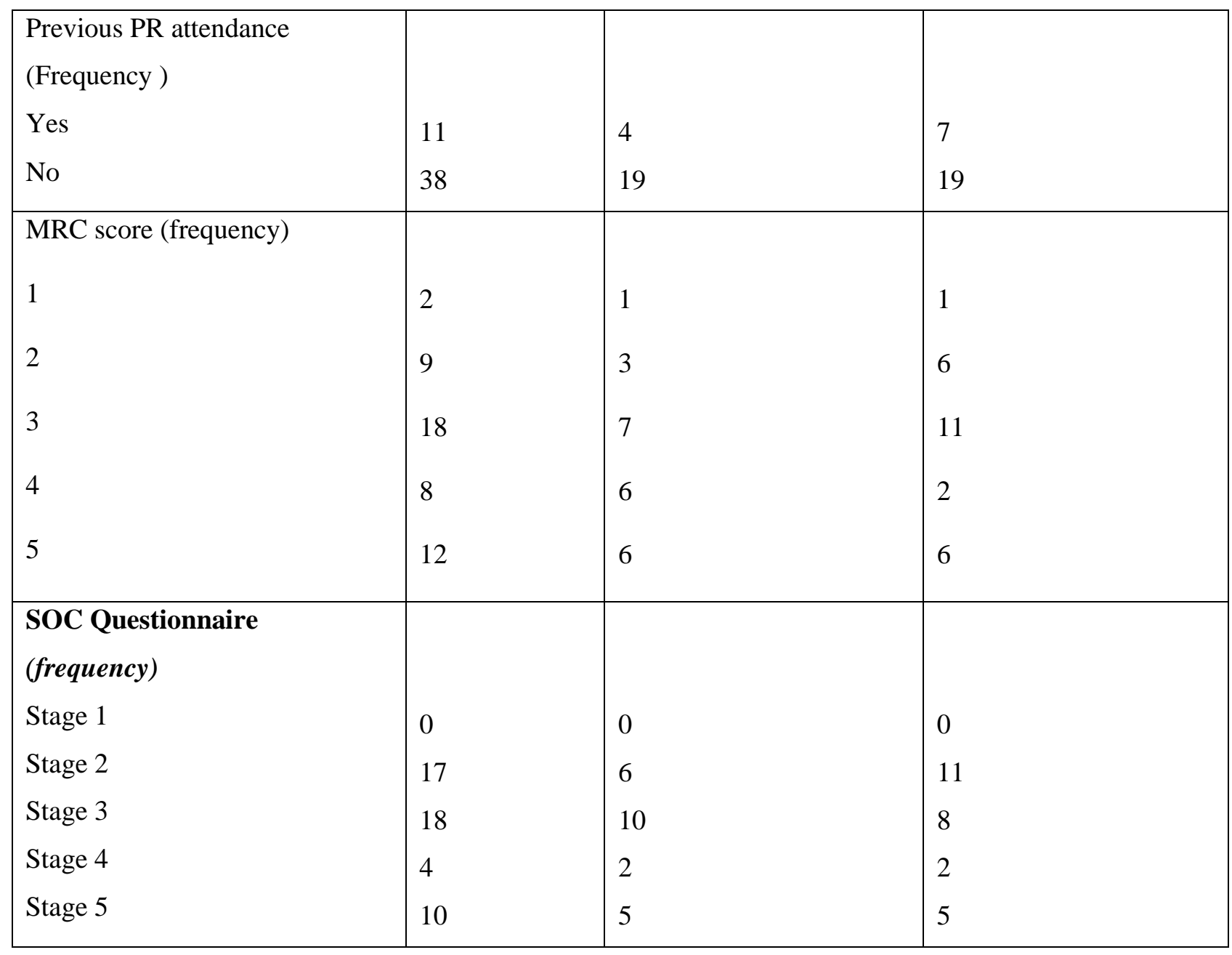

Regularly physically active relates to: Exercise e.g. weight training, aerobics for 20 minutes 3 times per week, OR Sport e.g. golf, hockey, netball, athletics, swimming for 20 minute 3 times per week, OR General e.g. walking, cutting the grass, vacuuming, washing the car accumulating to at least 30 minutes 5 times per week. SOC Questionnaire: Stage 1 - I am not regularly PA and do not intend to be so in the next 6months;

Stage 2 - I am not regularly PA but am thinking about starting to do so in the next 6 months; Stage 3 I do some PA but not enough to meet the description of regularly PA given above; Stage 4 -I am regularly PA but only began in the last 6 months; Stage 5 -I am regularly PA and have been for longer than 6 months. 
eTable 7 Available outcome measures at each time point and reasons for any missing data

\begin{tabular}{|c|c|c|c|c|c|c|}
\hline $\begin{array}{l}\text { Outcome Measure and reasons } \\
\text { for missing data }\end{array}$ & PAI Baseline $\mathrm{N}=23$ & PR Baseline $\mathrm{N}=26$ & $\begin{array}{l}\text { PAI Post intervention } \\
\mathrm{N}=18\end{array}$ & $\begin{array}{l}\text { PR Post intervention } \\
\mathrm{N}=19\end{array}$ & $\begin{array}{l}\text { PAI Follow up } \\
\mathrm{N}=15\end{array}$ & $\begin{array}{l}\text { PR Follow up } \\
\mathrm{N}=18\end{array}$ \\
\hline Actigraph & Available $\mathrm{N}=17$ & Available $\mathrm{N}=23$ & Available $\mathrm{N}=14$ & Available $\mathrm{N}=12$ & Available $\mathrm{N}=12$ & Available $\mathrm{N}=14$ \\
\hline $\begin{array}{l}\text { Not meeting wear time criteria (5 } \\
\text { days of ten hours) }\end{array}$ & $\mathrm{N}=3$ & $\mathrm{~N}=3$ & $\mathrm{~N}=2$ & $\mathrm{~N}=2$ & $\mathrm{~N}=2$ & $\mathrm{~N}=4$ \\
\hline $\begin{array}{l}\text { Patient non-compliant with } \\
\text { wearing device }\end{array}$ & $\mathrm{N}=1$ & & & & & \\
\hline Researcher error in download & $\mathrm{N}=2$ & & $\mathrm{~N}=1$ & $\mathrm{~N}=3$ & & \\
\hline Paper base outcomes only & & & $\mathrm{N}=1$ & $\mathrm{~N}=1$ & $\mathrm{~N}=1$ & \\
\hline Actigraph error & & & & $\mathrm{N}=1$ & & \\
\hline Pedometer & Available $\mathrm{N}=22$ & Available $\mathrm{N}=20$ & Available $\mathrm{N}=16$ & Available $\mathrm{N}=13$ & Available $\mathrm{N}=10$ & Available $\mathrm{N}=13$ \\
\hline $\begin{array}{l}\text { Not meeting wear time criteria ( } 5 \\
\text { days of } 100-50,000 \text { steps) }\end{array}$ & & $\mathrm{N}=6$ & $\mathrm{~N}=1$ & $\mathrm{~N}=5$ & $\mathrm{~N}=4$ & $\mathrm{~N}=5$ \\
\hline $\begin{array}{l}\text { Patient non-compliant with } \\
\text { wearing device }\end{array}$ & $\mathrm{N}=1$ & & & & & \\
\hline Paper based outcomes only & & & $\mathrm{N}=1$ & $\mathrm{~N}=1$ & $\mathrm{~N}=1$ & \\
\hline IPAQ & Available $\mathrm{N}=23$ & Available $\mathrm{N}=26$ & Available $\mathrm{N}=18$ & Available $\mathrm{N}=18$ & Available $\mathrm{N}=15$ & Available $\mathrm{N}=17$ \\
\hline Unable to complete (unwell) & & & & $\mathrm{N}=1$ & & $\mathrm{~N}=1$ \\
\hline
\end{tabular}




\begin{tabular}{|c|c|c|c|c|c|c|}
\hline GROC & & & Available $\mathrm{N}=13$ & Available $\mathrm{N}=13$ & Available $\mathrm{N}=11$ & Available $\mathrm{N}=9$ \\
\hline $\begin{array}{l}\text { Outcome measure added to CRF } \\
\text { after visit had been completed }\end{array}$ & & & $\mathrm{N}=4$ & $\mathrm{~N}=5$ & $\mathrm{~N}=4$ & $\mathrm{~N}=8$ \\
\hline Unable to complete (unwell) & & & $\mathrm{N}=1$ & $\mathrm{~N}=1$ & & $\mathrm{~N}=1$ \\
\hline CAT & Available $\mathrm{N}=23$ & Available $\mathrm{N}=26$ & Available $\mathrm{N}=27$ & Available $\mathrm{N}=19$ & Available $\mathrm{N}=15$ & Available $\mathrm{N}=18$ \\
\hline Not available in CRF & & & $\mathrm{N}=1$ & & & \\
\hline EQ5D5L & Available $\mathrm{N}=23$ & Available $\mathrm{N}=26$ & Available $\mathrm{N}=18$ & Available $\mathrm{N}=19$ & Available $\mathrm{N}=15$ & Available $\mathrm{N}=17$ \\
\hline Unable to complete (unwell) & & & & & & $\mathrm{N}=1$ \\
\hline ISWT & Available $\mathrm{N}=23$ & Available $\mathrm{N}=26$ & Available $\mathrm{N}=16$ & Available $\mathrm{N}=16$ & Available $\mathrm{N}=14$ & Available $\mathrm{N}=17$ \\
\hline $\begin{array}{l}\text { Paper based outcomes only } \\
\text { completed }\end{array}$ & & & $\mathrm{N}=1$ & $\mathrm{~N}=1$ & $\mathrm{~N}=1$ & \\
\hline Unable to travel & & & $\mathrm{N}=1$ & $\mathrm{~N}=1$ & & $\mathrm{~N}=1$ \\
\hline Removed- outlier & & & & $\mathrm{N}=1$ & & \\
\hline Semi structure interviews & & & Available $\mathrm{N}=16$ & Available $\mathrm{N}=16$ & & \\
\hline Paper based OMs only & & & $\mathrm{N}=1$ & $\mathrm{~N}=1$ & & \\
\hline Did not start intervention & & & & $\mathrm{N}=2$ & & \\
\hline Dropped out (study withdrawal) & & & $\mathrm{N}=5$ & $\mathrm{~N}=5$ & & \\
\hline Unable to travel & & & $\mathrm{N}=1$ & $\mathrm{~N}=1$ & & \\
\hline LTF & & & & $\mathrm{N}=2$ & & \\
\hline
\end{tabular}


eTable 8 Results of participant outcome measures (Actigraph, Sealed pedometer, IPAQ and GROC, ISWT, CAT and EQ5D5L) for the PAI group and PR group at baseline and post intervention. (mean (SD) [CI])

\begin{tabular}{|c|c|c|c|c|c|c|}
\hline $\begin{array}{l}\text { Outcome } \\
\text { measure }\end{array}$ & $\begin{array}{l}\text { Baseline } \\
\text { PAI } \\
(n=23)\end{array}$ & $\begin{array}{l}\text { Baseline } \\
\text { PR } \\
(n=26)\end{array}$ & $\begin{array}{l}\text { Post PAI } \\
(n=18)\end{array}$ & $\begin{array}{l}\text { Post PR } \\
(n=19)\end{array}$ & $\begin{array}{l}\text { Post } \\
\text { interventio } \\
\text { n-baseline } \\
\text { PAI }\end{array}$ & $\begin{array}{l}\text { Post } \\
\text { interventio } \\
\text { n-baseline } \\
\text { PR }\end{array}$ \\
\hline Actigraph & $\begin{array}{l}N=17(* n= \\
3, \Sigma n=1, \circledR n \\
=2)\end{array}$ & $\begin{array}{l}N=23 \\
(* n=3)\end{array}$ & $\begin{array}{l}N=14(* n=2, \\
\circledR n=1, \Sigma n=1\end{array}$ & 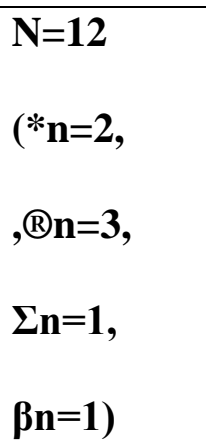 & $\mathrm{N}=12$ & $\mathrm{~N}=11$ \\
\hline Step count & $\begin{array}{l}3305.6 \\
(1960.2)\end{array}$ & $\begin{array}{l}3834.6 \\
(2245.5)\end{array}$ & $\begin{array}{l}4768.2 \\
(2992.1)\end{array}$ & $\begin{array}{l}3476.6 \\
(2307.9)\end{array}$ & $\begin{array}{l}972.0 \\
(3230.2) \\
{[-1080.3 \text { to }} \\
3024.4]\end{array}$ & $\begin{array}{l}4.3(662.7) \\
{[-440.9 \text { to }} \\
449.5]\end{array}$ \\
\hline $\begin{array}{l}\text { Total MVPA } \\
\text { time } \\
\text { (mins/day) }\end{array}$ & $14.3(15.3)$ & $\begin{array}{l}13.9 \\
(15.2)\end{array}$ & $24.49(26.0)$ & $\begin{array}{l}12.80 \\
(20.0)\end{array}$ & $\begin{array}{l}6.6(26.8) \\
{[-10.4 \text { to }} \\
23.7]\end{array}$ & $\begin{array}{l}0.9(6.0)[- \\
3.2 \text { to } 4.9]\end{array}$ \\
\hline $\begin{array}{l}\text { MVPA } 10+ \\
\text { number of } \\
\text { bouts }\end{array}$ & $0.05(0.1)$ & $.06(0.2)$ & $0.57(1.1)$ & $0.01(0.04)$ & $\begin{array}{l}0.5(1.0)[- \\
0.2 \text { to } 1.1]\end{array}$ & $\begin{array}{l}-0.03(0.1) \\
{[-0.1 \text { to }} \\
0.05]\end{array}$ \\
\hline
\end{tabular}




\begin{tabular}{|c|c|c|c|c|c|c|}
\hline $\begin{array}{l}\text { MVPA }_{10+} \\
\text { time } \\
\text { (mins/day) }\end{array}$ & $0.87(2.0)$ & $0.98(2.5)$ & $11.67(21.5)$ & $0.1(0.4)$ & $\begin{array}{l}9.1(20.2) \\
{[-3.8 \text { to }} \\
21.9]\end{array}$ & $\begin{array}{l}-0.4(1.4) \\
{[-1.3 \text { to }} \\
0.5]\end{array}$ \\
\hline $\begin{array}{l}\text { Physical } \\
\text { activity } \\
\text { category } \\
\text { sedentary }\end{array}$ & $\mathrm{N}=14$ & $\mathrm{~N}=17$ & $\mathrm{~N}=10$ & $\mathrm{~N}=11$ & & \\
\hline $\begin{array}{l}\text { Physical } \\
\text { activity } \\
\text { category Low } \\
\text { active }\end{array}$ & $\mathrm{N}=2$ & $\mathrm{~N}=4$ & $\mathrm{~N}=2$ & $\mathrm{~N}=0$ & & \\
\hline $\begin{array}{l}\text { Physical } \\
\text { activity } \\
\text { category } \\
\text { somewhat } \\
\text { active \& } \\
\text { above }\end{array}$ & $\mathrm{N}=1$ & $\mathrm{~N}=2$ & $\mathrm{~N}=2$ & $\mathrm{~N}=1$ & & \\
\hline Pedometer & $\begin{array}{l}\mathbf{N}=22 \\
(\Sigma n=1) \\
3044.4 \\
(1871.1)\end{array}$ & $\begin{array}{l}\mathbf{N}=\mathbf{2 0}(* \mathbf{n} \\
=6) \\
3264.01 \\
(1907.3)\end{array}$ & $\begin{array}{l}\mathbf{N}=16 \\
(* \mathbf{n}=1, \pi \\
\mathbf{n}=\mathbf{1}) \\
5570.7 \\
(3486.7)\end{array}$ & $\begin{array}{l}\mathbf{N}=\mathbf{1 3} \\
\left(*_{\mathbf{n}}=\mathbf{5}, \boldsymbol{\pi}\right. \\
\mathbf{n}=\mathbf{1}) \\
3917.5 \\
(2194.9)\end{array}$ & $\begin{array}{l}\mathbf{N}=16 \\
2310.3 \\
(3614.7) \\
{[384.2 \text { to }} \\
4236.4]\end{array}$ & $\begin{array}{l}\mathbf{N}=13 \\
146.9 \\
(1605.7) \\
823.4 \text { to } \\
1117.2]\end{array}$ \\
\hline IPAQ & & & & $\begin{array}{l}\mathrm{N}=18(\Sigma \\
\mathrm{n}=\mathbf{1})\end{array}$ & $\mathrm{N}=18$ & $\mathrm{~N}=18$ \\
\hline
\end{tabular}




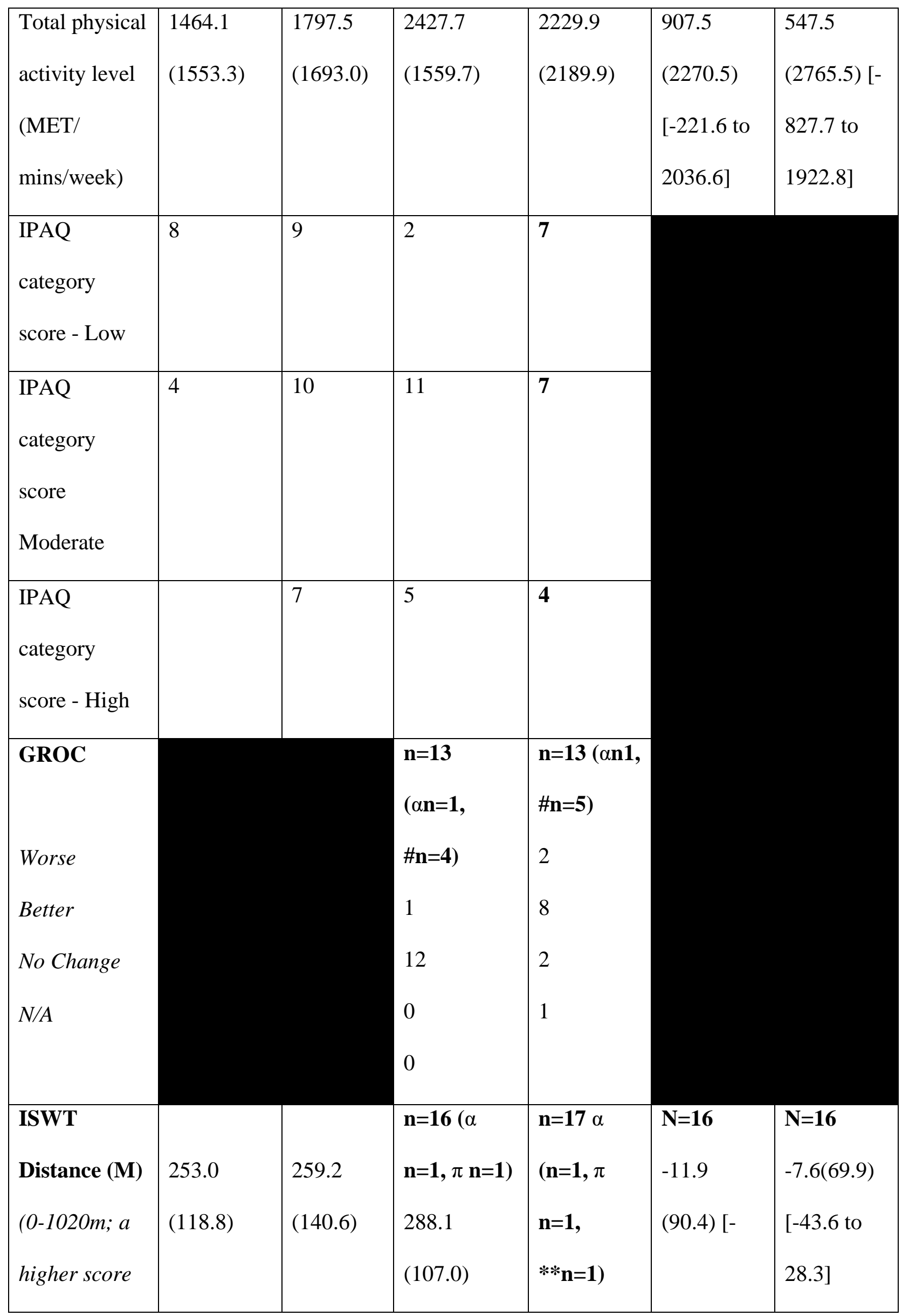




\begin{tabular}{|c|c|c|c|c|c|c|}
\hline $\begin{array}{l}\text { indicates a } \\
\text { higher } \\
\text { exercise } \\
\text { capacity) }\end{array}$ & & & & $\begin{array}{l}280.0 \\
(139.7)\end{array}$ & $\begin{array}{l}60.1 \text { to } \\
36.3]\end{array}$ & \\
\hline $\begin{array}{l}\text { CAT } \\
(0-40 ; a \\
\text { higher score } \\
\text { indicates a } \\
\text { higher } \\
\text { severity) }\end{array}$ & $23.8(6.9)$ & $18.7(7.3)$ & $\begin{array}{l}\mathbf{n}=\mathbf{1 7}(\Omega \\
\mathbf{n}=\mathbf{1}) \\
22.5(7.0)\end{array}$ & $16.6(5.3)$ & $\begin{array}{l}\mathbf{N}=\mathbf{1 7} \\
0.6(7.7)[- \\
3.3 \text { to } 4.6]\end{array}$ & $\begin{array}{l}\mathbf{N}=19 \\
-0.4(6.4) \\
{[-3.5 \text { to }} \\
2.7]\end{array}$ \\
\hline $\begin{array}{l}\text { EQ-5D } \\
\text { Weighted } \\
\text { Health Index } \\
\text { (UK value } \\
\text { sets - higher } \\
\text { score } \\
\text { indicates } \\
\text { better health- } \\
\text { related } \\
\text { quality of life) }\end{array}$ & $0.5(0.2)$ & $0.6(0.3)$ & $0.5(0.3)$ & $0.7(0.2)$ & $\begin{array}{l}\mathbf{N}=\mathbf{1 8} \\
-0.003 \\
(0.2)[-0.1 \\
\text { to } 0.1]\end{array}$ & $\begin{array}{l}\mathbf{N}=19 \\
0.1(0.2)[- \\
0.02 \text { to } \\
0.2]\end{array}$ \\
\hline $\begin{array}{l}\text { EQ5D } \\
\text { Health state } \\
\text { VAS (0-100; } \\
\text { a higher the } \\
\text { score }\end{array}$ & $56.2(20.8)$ & $\begin{array}{l}60.8 \\
(12.3)\end{array}$ & $58.6(23.0)$ & 74.0 (19.9) & $\begin{array}{l}\mathbf{N}=18 \\
2.6(35.2) \\
{[-14.9 \text { to }} \\
20.1]\end{array}$ & $\begin{array}{l}\mathbf{N}=19 \\
13.3[-0.9 \\
\text { to } 27.4]\end{array}$ \\
\hline
\end{tabular}




\begin{tabular}{|l|l|l|l|l|l|l|}
\hline indicates & & & & & & \\
better health & & & & & & \\
status) & & & & & & \\
\hline
\end{tabular}

*Not meeting criteria (Actigraph: 5 days of ten hours wear time, pedometer: 100-50,000 steps recorded) $\Sigma$ patient non-compliant with wearing device ${ }^{\circledR}$ researcher download error. $\pi$ : paper based outcomes only completed. $\beta$ Actigraph error, $\alpha$ :unable to travel as unwell and unable to travel, \# outcome measure added to CRF post visit $\Omega$ Outcome measure not available in CRF, $\alpha$ :unable to complete as unwell and unable to travel, ${ }^{*} \mathrm{n}=1$ outlier 
Table 1 National Institute for Health Research Success Criteria for a feasibility trial*

\begin{tabular}{|l|c|l|}
\hline Criteria & Present & \multicolumn{1}{|c|}{ Comment } \\
\hline Number of eligible patients. & $\checkmark$ & See Table 2. \\
\hline Willingness of participants to be randomised. & $\checkmark$ & Yes all patients were willing to be \\
randomised; one participant attended \\
the incorrect allocation.
\end{tabular}

*relevant criteria only for this study included 
Table 2 Baseline demographics and characteristics of participants

\begin{tabular}{|c|c|c|c|}
\hline $\begin{array}{c}\text { Baseline } \\
\text { Demographic } \\
\text { Characteristics }\end{array}$ & $\begin{array}{l}\text { Whole population } \\
\mathrm{N}=49\end{array}$ & $\begin{array}{l}\text { Physical Activity } \\
\text { Intervention } \mathrm{N}=23\end{array}$ & $\begin{array}{l}\text { Pulmonary } \\
\text { Rehabilitation N=26 }\end{array}$ \\
\hline $\begin{array}{l}\text { Age (years) } \\
\text { Mean }( \pm S D)\end{array}$ & $64.4(8.6)$ & $61.1(8.5)$ & $67.2(7.8)$ \\
\hline Gender (M:F) & $24: 25$ & $13: 10$ & $11: 15$ \\
\hline $\begin{array}{l}\mathrm{FEV}_{1} \mathrm{~L} / \mathrm{min} \text { Mean } \\
( \pm \mathrm{SD})\end{array}$ & $1.4(0.6)$ & $1.4(0.6)$ & $1.4(0.6)$ \\
\hline $\mathrm{FEV}_{1} \%$ predicted & $56(23) \%$ & $54(23) \%$ & $57(24) \%$ \\
\hline $\mathrm{FEV}_{1} / \mathrm{FVC}( \pm \mathrm{SD})$ & $0.5(0.2)$ & $0.5(0.2)$ & $0.5(0.2)$ \\
\hline $\begin{array}{l}\text { GOLD spirometry } \\
\text { classification }\end{array}$ & & & \\
\hline $\begin{array}{l}\text { Mild } \\
\text { Moderate } \\
\text { Severe } \\
\text { Very severe }\end{array}$ & $\begin{array}{l}8 \\
18 \\
18 \\
5\end{array}$ & $\begin{array}{l}3 \\
7 \\
11 \\
2\end{array}$ & $\begin{array}{l}5 \\
11 \\
7 \\
3\end{array}$ \\
\hline $\begin{array}{l}\text { Daily steps } \\
\text { (Actigraph) }\end{array}$ & $\begin{array}{l}3609.8(2119.2) \\
\mathbf{N}=\mathbf{4 0} \\
(* \mathbf{n}=\mathbf{6}, \mathbf{\Sigma} \mathbf{n}=\mathbf{1}, \circledast \mathbf{n}=\mathbf{2})\end{array}$ & $\begin{array}{l}3305.6(1960.2) \\
\mathbf{N}=\mathbf{1 7}(* \mathbf{n}=\mathbf{3}, \mathbf{\Sigma} \mathbf{n}=\mathbf{1},(\mathbf{n}=\mathbf{2})\end{array}$ & $\begin{array}{l}3834.6(2245.5) \\
\mathbf{N}=\mathbf{2 3}(* \mathbf{n}=\mathbf{3})\end{array}$ \\
\hline ISWT & $256.3(129.5)$ & $253.0(118.8)$ & $259.2(140.6)$ \\
\hline
\end{tabular}

*Not meeting criteria (Actigraph: 5 days of ten hours wear time, pedometer: 100-50,000 steps recorded) $\Sigma$ patient non-compliant with wearing device ${ }^{\circledR}$ researcher download error. 